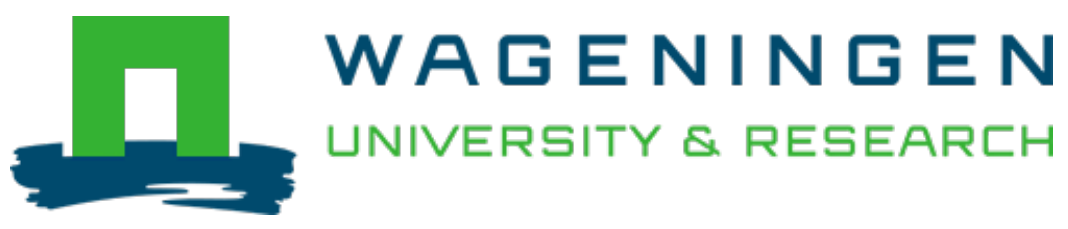

\title{
Yield Response of an Ensemble of Potato Crop Models to Elevated CO2 in Continental Europe
}

\author{
European Journal of Agronomy \\ Fleischer, D.; Condori, B.; Barreda, C.; Berghuijs, H.N.C.; Bindi, M. et al \\ https://doi.org/10.1016/j.eja.2021.126265
}

This article is made publicly available in the institutional repository of Wageningen University and Research, under the terms of article $25 \mathrm{fa}$ of the Dutch Copyright Act, also known as the Amendment Taverne. This has been done with explicit consent by the author.

Article 25 fa states that the author of a short scientific work funded either wholly or partially by Dutch public funds is entitled to make that work publicly available for no consideration following a reasonable period of time after the work was first published, provided that clear reference is made to the source of the first publication of the work.

This publication is distributed under The Association of Universities in the Netherlands (VSNU) 'Article $25 \mathrm{fa}$ implementation' project. In this project research outputs of researchers employed by Dutch Universities that comply with the legal requirements of Article $25 \mathrm{fa}$ of the Dutch Copyright Act are distributed online and free of cost or other barriers in institutional repositories. Research outputs are distributed six months after their first online publication in the original published version and with proper attribution to the source of the original publication.

You are permitted to download and use the publication for personal purposes. All rights remain with the author(s) and / or copyright owner(s) of this work. Any use of the publication or parts of it other than authorised under article $25 \mathrm{fa}$ of the Dutch Copyright act is prohibited. Wageningen University \& Research and the author(s) of this publication shall not be held responsible or liable for any damages resulting from your (re)use of this publication.

For questions regarding the public availability of this article please contact openscience.library@wur.nl 


\section{Yield Response of an Ensemble of Potato Crop Models to Elevated $\mathrm{CO}_{2}$ in Continental Europe}

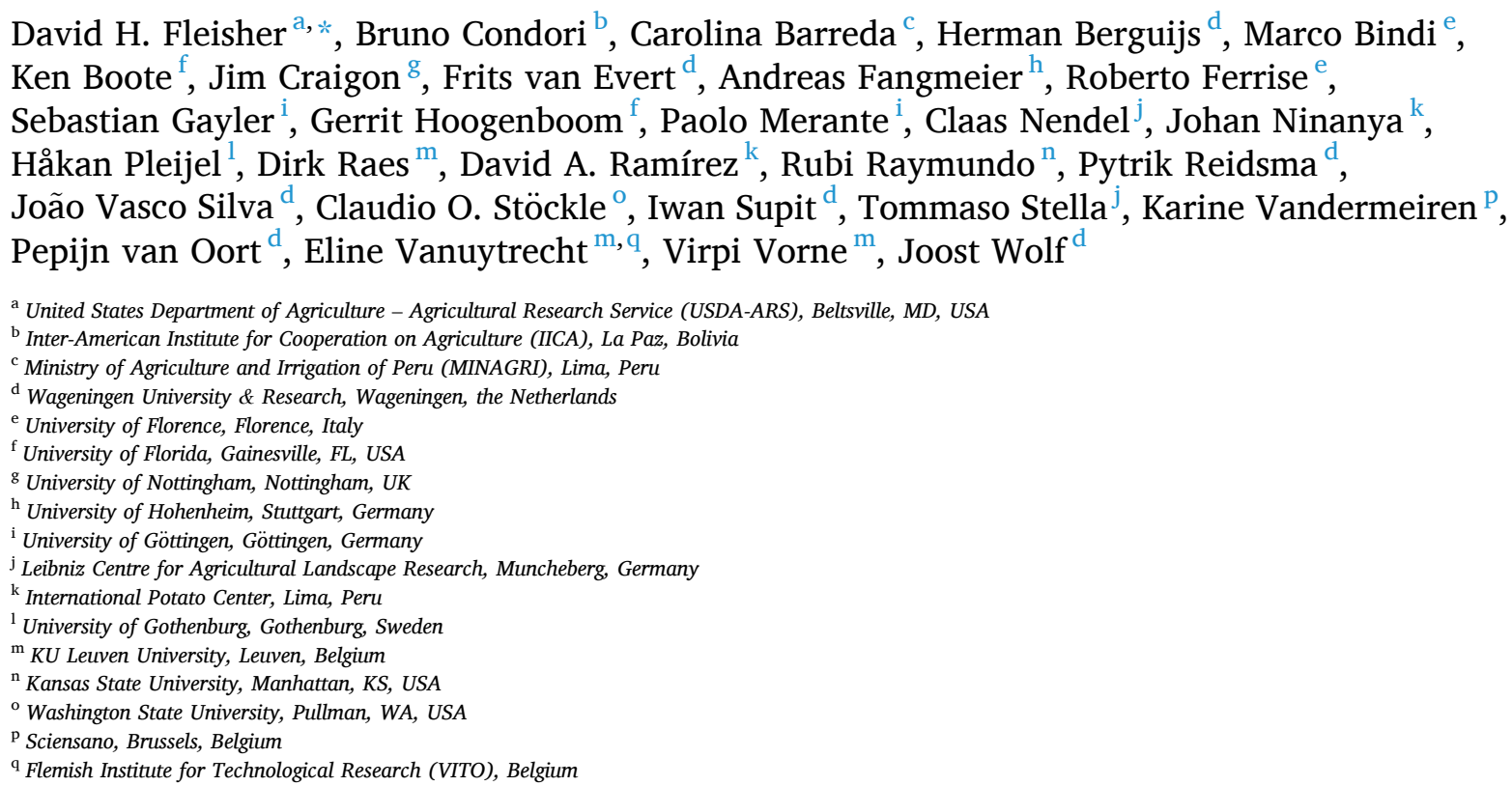

A R T I C L E I N F O

\section{Keywords:}

Multi-model ensemble

Food security

Climate change

Crop modeling

\begin{abstract}
A B S T R A C T
A multi-model inter-comparison study was conducted to evaluate the performance of ten potato crop models to accurately predict potato yield in response to elevated $\mathrm{CO}_{2}(\mathrm{Ce})$ when calibrated with ambient $\mathrm{CO}_{2}$ data $(\mathrm{Ca})$. Experimental data from seven open-top chambers (OTC) and free-air- $\mathrm{CO}_{2}$-enrichment (FACE) facilities across continental Europe were used. Model ensemble percent errors averaged over all datasets for simulated yields were $26.5 \%$ for Ca and $27.2 \%$ Ce data. Metrics such as Wilmott's index of agreement (IA) and root mean square relative error (RMSRE) ranged broadly among individual models and locations, such that four of the ten models outperformed the median or mean of the ensemble for about half of the Ce datasets. These top performing models were representative of three different model structural groups, including radiation use efficiency, transpiration efficiency, or leaf-level based approaches. Relative response to an increase in $\mathrm{CO}_{2}$ was more accurately modeled than absolute yield responses when averaged across all locations, and within $3.3 \mathrm{~kg} \mathrm{ppm}^{-1}$ (or $5 \%$ ) of observed values. Specific targets in the model structure needed for improvement were not identified due to large and inconsistent variation in the accuracy of yield predictions across locations. However, models with the lowest calibration errors tended to be top performers for Ce predictions as well. Such results suggest calibration is at least as important as model structure. Where possible, modelers using potato models to estimate Ce responses should use Ce calibration data to improve confidence in such predictions.
\end{abstract}

Abbreviations: $\mathrm{Ca}$, ambient atmospheric carbon dioxide concentration; Ce, elevated atmospheric carbon dioxide concentration; $\mathrm{CO}_{2}$, atmospheric carbon dioxide

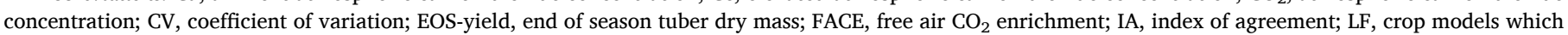

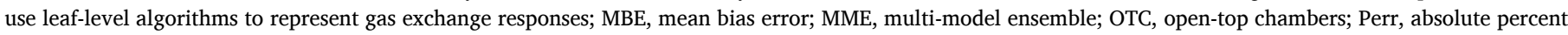
error; RMSE, root mean square error; RMSRE, root mean square relative error; RUE, radiation use efficiency; TE, transpiration efficiency.

* Corresponding author.

E-mail address: david.fleisher@usda.gov (D.H. Fleisher). 


\section{Introduction}

Process-level crop models are increasingly used to project climate change impacts on food security (e.g. Ahmad et al., 2020; Chen et al., 2020; Resop et al., 2016; Wang et al., 2020; Xiao et al., 2020). Recent literature uses projections from a single model to estimate the magnitude of such effects on yield and other response variables. However, a strong case can be made for using estimates from a group of models, referred to as a multi-model ensemble (MME), instead of individual models (Wallach et al., 2016) for many of these research studies. Recent crop model inter-comparison studies with maize (Bassu et al., 2014), potato (Fleisher et al., 2017), rice (Li et al., 2015), sugarcane (Marin et al., 2015), and wheat (Asseng et al., 2013; Martre et al., 2015) concluded that the MME median or mean consistently out-performed any individual model in terms of accuracy when compared across varying management treatments, locations and/or climate conditions. Model inter-comparison studies primarily consist of comparisons of simulated yields to projected, but not observed, changes in $\mathrm{CO}_{2}$, air temperature, and rainfall. Carter (2013) noted that although estimates from a sufficiently large MME tend to converge around a projected yield value for $\mathrm{CO}_{2}$ response, convergence does not imply better accuracy or measure of 'true yield'. Thus, the use of MME for simulated climate responses does not guarantee a better representation of real-world data (Asseng et al., 2013), and more effort is required to understand single and ensemble model responses to measured climate change responses, such as elevated $\mathrm{CO}_{2}(\mathrm{Ce})$.

Nearly all crop models incorporate methods to respond to direct effects of $\mathrm{CO}_{2}$ on assimilation and/or transpiration rate. Approaches vary considerably and range from radiation use efficiency (RUE) and transpiration efficiency (TE) methods to mechanistic leaf-to-canopy level (LF) photosynthesis scaling algorithms (e.g. Boote et al., 2013). Regardless of methodology, Tubiello and Ewert (2002) indicated most models have not fully tested the simulation of crop growth and yield using empirical data under Ce conditions, a situation that appears to remain even more relevant today with the $\mathrm{CO}_{2}$ concentration of the atmosphere reaching $400 \mathrm{ppm}$ in 2013 . The availability of appropriate data remains a significant obstacle for vigorous model evaluation for $\mathrm{CO}_{2}$ responses under field conditions (Boote et al., 2015). There is substantial literature regarding experimentally measured crop responses to climate change factors, most having been conducted within controlled environment facilities. These data are frequently used to develop and test model sub-components (e.g. Dathe et al., 2014; Kim et al., 2012), but may not be as well-suited for rigorous whole model validation studies. In this regard, the use of electric lighting with differing spectral qualities and intensity than sunlight, enclosure effects, controlled environment, specific cultural systems, and other artifacts may affect direct transferability to field conditions (Fleisher et al., 2010a; Kimball, 2011). Evaluation and testing of model subroutines or components associated with $\mathrm{CO}_{2}$ response does not necessarily imply validation for projection of crop growth or yields under field conditions (Tubiello and Ewert, 2002).

Studies by Van Oijen and Ewert (1999) and Ewert et al. (2002) used data from open top chambers (OTC) and free-air $\mathrm{CO}_{2}$ enrichment (FACE) facilities to evaluate simulated wheat yield responses. A two model ensemble was used in Van Oijen and Ewert (1999) and a three model ensemble in Ewert et al. (2002). Models were calibrated using experimental data from ambient $\mathrm{CO}_{2}(\mathrm{Ca})$ treatments, so that ability of models to extrapolate the effects of a $\mathrm{CO}_{2}$ increase on grain yield could be fully evaluated. Wolf and Van Oijen (2003) assessed the accuracy of a single potato model using data from OTC and FACE facilities when calibrated in a similar procedure as the prior two studies. More recently, a maize MME study comprised of 21 models was conducted by Durand et al. (2018) for predicting Ce and water availability interactions. Half of the models were within $1 \mathrm{Mg} \mathrm{ha}^{-1}$ of the observed grain yield mean, and the MME median showed a small bias of less than $1 \mathrm{Mg} \mathrm{ha}^{-1}$. A rice MME comparison was conducted by Hasegawa et al. (2017) using FACE and soil-plant-atmosphere research (SPAR) chamber data. The authors also observed accurate representation of MME predicted grain yield under both $\mathrm{Ca}$ and Ce conditions. However, a large variability (as large as $50 \%$ difference for observed versus predicted yields) was observed among individual rice models for Ce responses. Modelers were given access to both $\mathrm{Ca}$ and Ce data in a few of these studies, which were used to test, improve, and calibrate models before contributing results. This particular experimental design, however, confounds the ability to truly evaluate predicted Ce responses of MME and individual models as compared to the more typical situation where observed Ce data are not available for the study space in question.

Considerably fewer model inter-comparison and evaluation studies have been conducted with tuber / root crops such as potato as compared with cereal grains (Fleisher et al., 2017). In the current study, the European CHIP potato project data (De Temmerman et al., 2002a) were used to evaluate ten potato models' ability to mimic yield responses for the same cultivar across seven continental European locations. The models were first tested to replicate Ca response using a single calibration parameter set across all locations. Accuracy of individual model and MME predictions were then evaluated for Ce responses using the same calibration set. The study hypothesis was that MME mean and/or median would provide more accurate yield predictions than individual models. It was expected to observe similar levels of uncertainty, or model variability, for $\mathrm{Ca}$ and Ce yield estimates, as other studies have shown that model agreement within an MME is relatively constant with respect to rising atmospheric carbon dioxide concentration $\left(\mathrm{CO}_{2}\right)$ (e.g. Asseng et al., 2013; Bassu et al., 2014; Fleisher et al., 2017; Li et al., 2015). Finally, large differences due to location on these responses were expected as observed by other studies in which cross-location calibration methods were tested such as Van Oijen and Ewert (1999); Wolf and Van Oijen (2002), and Ewert et al. (2002). Specific objectives were thus to evaluate the (1) accuracy of a potato MME to simulate Ce yield responses when calibrated with Ca data, (2) extent of variation within the MME and the influence of model structure on these results, and (3) effect of location on accuracy and model agreement. Results will help to identify areas of weakness among current potato models to capture elevated $\mathrm{CO}_{2}$ responses across a regional scale and indicate the utility of using ensemble approaches for climate change projections.

\section{Materials and methods}

\subsection{Experimental data}

Data from the European CHIP experiment (De Temmerman et al., 2002a) included one or two years of measured potato (S. tuberosum L. cv. Bintje) yield at seven locations across continental Europe at $\mathrm{Ca}(\approx 379$ $\mathrm{ppm})$ or Ce $(\approx 624 \mathrm{ppm})$ levels (Table 1). Experimental facilities included open-top chambers (OTC) and free-air $\mathrm{CO}_{2}$ enrichment (FACE) systems. OTCs were used at six of the locations and FACE systems were maintained only at the Germany and Italy locations. The Germany location included both OTC and FACE facilities. Altogether, there were 28 combinations of experimental data, or datasets. Each dataset was assigned a seven-letter code consisting of facility type (F - FACE or O OTC), location (e.g. IT - Italy, UK - the United Kingdom), $\mathrm{CO}_{2}$ concentration (Ca or Ce), and year (98-1998 or 99-1999). For example, 'FITCa98' referred to the FACE study in Italy under an ambient $\mathrm{CO}_{2}$ concentration in 1998. All Ca and Ce treatment levels are defined in Table 1 and seasonal environmental averages are shown in Table 2.

Standardized management practices with regards to potato seedpiece size, cultural practice, and planting densities were followed at all locations (De Temmerman et al., 2002a). Fertilization (Table 2) and irrigation were supplied with a goal of providing optimum nutrient and water supply. Climate data was obtained from on-site weather stations and aggregated to a 24-h time step in the current study for daily solar radiation, daily maximum or minimum air temperature, daily rainfall rate, and $\mathrm{CO}_{2}$ concentration (Table 2). Initial conditions for soil 
moisture, prior crop residue, and nitrogen were not available from experimental data. They were obtained, with permission, from Raymundo et al. (2017). Measured crop data included end-of-season tuber yield (both dry and fresh weight) for each year. Certain locations included time-series data for above-ground biomass, including leaf and stem dry weight.

\subsection{Potato models and calibration protocol}

Ten modeling groups volunteered to use their dynamic crop simulation model, each of which required evidence of prior peer-review. Details regarding the structure for each model, along with the primary reference associated with the description of each model, were summarized in Table 3. Models were loosely classified into three broad groups with respect to incorporation of direct $\mathrm{CO}_{2}$ response including those employing radiation use efficiency (RUE, $n=6$ ), leaf-level ( $L F, n=3$ ), or transpiration efficiency (TE) $(n=1)$ bases. RUE groups use an empirically derived multiplier to adjust daily carbon gain based on $\mathrm{CO}_{2}$ level (e.g. Hoogenboom et al., 2015) and TE groups use a similar approach to modify the estimate of water productivity (e.g. Steduto et al., 2009). In leaf-level methods, atmospheric $\mathrm{CO}_{2}$ concentration directly affects photosynthetic rate which is usually coupled with stomatal conductance and transpiration via an energy balance as in Kim and Lieth (2003). These methods generally fall under the "P-R" gross photosynthesis respiration approaches for light utilization in Table 3.

The complete set of Ca data at each location was made available to each modeling group. Modelers were required to independently develop input files in the format for their models, conduct calibration and/or evaluation using standard practice, execute the assigned model runs, and deliver model output data to the primary author. Modelers were tasked with obtaining a single common set of calibration values to be applied to all locations. Each modeling group was composed of scientists directly involved in source code development and/or maintenance of their particular model and used their own specific procedures for their calibration approach. Specific calibration methods thus varied among modeling groups and included manual and/or automated procedures for minimizing differences between predicted versus observed values via the use of 'genetic coefficients'. Genetic coefficients in these models represent crop phenotype response to weather and management factors (Fleisher et al., 2020). A list of the major genetic coefficients calibrated for each model, their resulting values, and the institute of each modeling group that performed the calibration was shown in supplemental Table $\mathrm{S} 1$. A range of calibration values obtained when the model was calibrated for each individual location was also provided; however, only the common set of calibration values across all locations was used for this study. Each group then simulated Ce responses for each site using this common calibration with no further modifications. All these model application research tasks were conducted for each model only by members of the development team associated with that particular model.

\subsection{Analysis}

A code, M1 through M10, was assigned to each model to improve legibility in tables and figures. The multi-model ensemble (MME) mean and median response were represented in figures and tables by 'mean' or 'median' respectively, which were obtained by aggregating across individual model results for the given dataset or location. Custom R scripts (version 3.5.1) written in RStudio (vs 1.21335) were used to analyze results for end-of-season tuber dry yield (EOS-yield). Multiple metrics were utilized including absolute percent error (Perr), mean bias error (MBE), root mean square error (RMSE), root mean square relative error (RMSRE), and index of agreement (IA, (Willmott et al., 2012)). Perr was calculated as in Eq. (1), where $S$ refers to simulated and $\mathrm{O}$ observed EOS-yield.

$P_{\text {err }}=\frac{|O-S|}{O} \times 100$

MBE (eqn 2) was pooled across all datasets for each model at each $\mathrm{CO}_{2}$ level, where $\mathrm{n}=$ number of datasets for each $\mathrm{CO}_{2}$ level (14). MBE indicated the direction and magnitude of bias (tendency to under- or over-predict yield) such that negative values indicate under-prediction.

$M B E=\frac{\sum_{i}^{n}\left(S_{i}-O_{i}\right)}{n}$

RMSE showed the absolute magnitude of error while RMRSE normalized this term by dividing by the observed mean for each dataset to account for the wide range in observed yield across locations as in Martre et al. (2015) (eqn (3), with variables as defined previously).

$R M S E=\sqrt{n^{-1} \sum_{i=1}^{n}\left(O_{i}-S_{i}\right)^{2}} ; R M S R E=100 x \sqrt{n^{-1} \sum_{i=1}^{n}\left(\frac{O_{i}-S_{i}}{O_{i}}\right)^{2}}$

IA is the ratio of mean square error and potential error, in which a value of 1 describes a perfect correspondence between simulated and observed values while a 0 value means that no agreement was found. In Eq. (4), $\bar{O}$ is the mean of observed values.

$$
\mathrm{IA}=1-\frac{\sum_{i=1}^{n}\left(O_{i}-S_{i}\right)^{2}}{\sum_{i=1}^{n}\left(\left|S_{i}-\bar{O}\right|+\left|O_{i}-\bar{O}\right|\right)^{2}}
$$

Slopes of the 1:1 plot fit through the origin were used to evaluate over or under-estimation of yield for individual models and the MME across all locations. The coefficient of variation (CV) among models was computed as an indication of variability (uncertainty) among model

Table 1

Overview of CHIP experimental data including locations, experiment facility (OTC $=$ open top chamber; $\mathrm{FACE}=$ free air $\mathrm{CO}_{2}$ enrichment), $\mathrm{CO}_{2}$ treatment set-points $(\mathrm{Ca}$ - ambient; Ce - elevated), in-season harvest numbers, and naming conventions used in this study.

\begin{tabular}{|c|c|c|c|c|c|c|c|c|c|c|}
\hline \multirow[t]{2}{*}{ Location } & \multirow[t]{2}{*}{ Lat } & \multirow[t]{2}{*}{ Long } & \multicolumn{2}{|c|}{$\begin{array}{l}\text { Type of } \\
\text { Experiment }\end{array}$} & \multicolumn{2}{|c|}{$\begin{array}{l}\text { Target } \mathrm{CO}_{2}(\mathrm{ppm}) \\
\text { concentration }\end{array}$} & \multicolumn{2}{|c|}{$\begin{array}{l}\text { \#Time-series } \\
\text { harvests }^{[\mathrm{b}]}\end{array}$} & \multirow[t]{2}{*}{ Code } & \multirow[t]{2}{*}{ Dataset Names } \\
\hline & & & OTC & FACE & $\mathrm{Ca}$ & $\mathrm{Ce}$ & 1998 & 1999 & & \\
\hline Rapolano, Italy & $43^{\circ} 17^{\prime} \mathrm{N}$ & $11^{\circ} 39^{\prime} \mathrm{E}$ & - & Yes & 370 & 550 & 5 & 5 & IT & FITCa98,99 FITCe98,99 \\
\hline Giessen, Germany $^{[\mathrm{c}]}$ & $50^{\circ} 34^{\prime} \mathrm{N}$ & $8^{\circ} 40^{\prime} \mathrm{E}$ & Yes & Yes & 370 & $680 / 550$ & 2 & 2 & GE & OGECa98,99 OGECe98,99 FGECa98,99 FGECe98,99 \\
\hline Tervuren, Belgium & $50^{\circ} 50^{\prime} \mathrm{N}$ & $4^{\circ} 31^{\prime} \mathrm{E}$ & Yes & - & 370 & 680 & 2 & 2 & $\mathrm{BE}$ & OBECa98,99 OBECe98,99 \\
\hline Sutton Bonington, UK & $52^{\circ} 45^{\prime} \mathrm{N}$ & $1^{\circ} 15^{\prime} \mathrm{W}$ & Yes & - & 370 & 680 & 3 & 2 & UK & OUKCa98,99 OUKCe98,99 \\
\hline Carlow, Ireland & $52^{\circ} 51^{\prime} \mathrm{N}$ & $6^{\circ} 54^{\prime} \mathrm{W}$ & Yes & - & 370 & 680 & 2 & 2 & IR & OIRCa98,99 OIRCe98,99 \\
\hline Goteborg, Sweden & $57^{\circ} 54^{\prime} \mathrm{N}$ & $12^{\circ} 24^{\prime} \mathrm{E}$ & Yes & - & 370 & 680 & 1 & - & sw & OSWCa98 OsWCe98 \\
\hline Jokioinen, Finland & $60^{\circ} 50^{\prime} \mathrm{N}$ & $23^{\circ} 28^{\prime} \mathrm{E}$ & Yes & - & 370 & 680 & - & 2 & FI & OFICa99 OFICe99 \\
\hline
\end{tabular}

[a] Values were $\mathrm{CO}_{2}$ treatment levels setpoints. Measured values were summarized in Table 2.

[b] Including end-of-season harvest data.

[c] Pot experiments with transparent rainout shelter. $\mathrm{CO}_{2}$ setpoints were $680 \mathrm{ppm}$ for OTC and 550 ppm for FACE system. 
Table 2

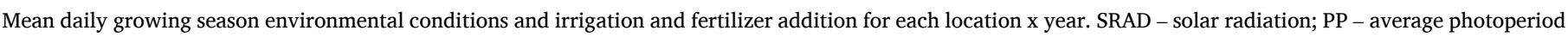

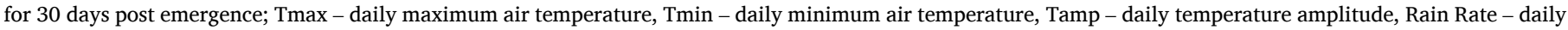
rainfall, Irr Rate - daily irrigation, $\mathrm{Ca}$ - ambient $\mathrm{CO}_{2}$ concentration, $\mathrm{Ce}$ - elevated $\mathrm{CO}_{2}$ concentration, Fert - total inorganic fertilizer.

\begin{tabular}{|c|c|c|c|c|c|c|c|c|c|c|c|}
\hline Location $^{[\mathrm{a}]}$ & Year & $\begin{array}{l}\text { SRAD } \\
\text { MJ m }{ }^{-2} \mathrm{~d}^{-1}\end{array}$ & $\begin{array}{l}\text { PP } \\
h\end{array}$ & $\begin{array}{l}\text { Tmax } \\
{ }^{\circ} \mathrm{C}\end{array}$ & $\begin{array}{l}\text { Tmin } \\
{ }^{\circ} \mathrm{C}\end{array}$ & $\begin{array}{l}\text { Tamp } \\
{ }^{\circ} \mathrm{C}\end{array}$ & $\begin{array}{l}\text { Rain Rate } \\
\mathrm{mm} \mathrm{d}^{-1}\end{array}$ & $\begin{array}{l}\text { Irr Rate } \\
\mathrm{mm} \mathrm{d}^{-1}\end{array}$ & $\begin{array}{l}\mathrm{Ca} \\
\mathrm{ppm}\end{array}$ & $\begin{array}{l}\mathrm{Ce} \\
\mathrm{ppm}\end{array}$ & $\begin{array}{l}\text { Fert } \\
\mathrm{kg} \mathrm{N} \mathrm{ha}^{-1}\end{array}$ \\
\hline \multirow[t]{2}{*}{ FGE } & 1998 & 16.5 & 16.2 & 21.1 & 10.0 & 11.1 & 1.9 & 1.0 & 395 & 428 & 150 \\
\hline & 1999 & 19.2 & 16.2 & 22.4 & 10.5 & 11.9 & 0.8 & 3.0 & 374 & 487 & 157 \\
\hline \multirow[t]{2}{*}{ FIT } & 1998 & 21.0 & 15.2 & 28.7 & 11.1 & 17.5 & 1.0 & [c] & 369 & 555 & 250 \\
\hline & 1999 & 20.2 & 15.2 & 26.6 & 10.7 & 15.9 & 1.3 & [c] & 367 & 553 & 249 \\
\hline \multirow[t]{2}{*}{ OBE } & 1998 & 14.4 & 16.1 & 22.9 & 12.1 & 10.8 & 3.2 & 2.9 & 371 & 650 & 205 \\
\hline & 1999 & 16.5 & 16.1 & 24.7 & 12.5 & 12.2 & 1.2 & 2.4 & 387 & 657 & 220 \\
\hline OFI & 1999 & 13.0 & 19.0 & 26.2 & 9.4 & 16.7 & 0.7 & 0.0 & 368 & 680 & 80 \\
\hline \multirow[t]{2}{*}{$\mathrm{OGE}^{[\mathrm{b}]}$} & 1998 & 9.6 & 16.2 & 26.8 & 13.3 & 13.5 & 0.0 & 3.0 & 375 & 643 & 150 \\
\hline & 1999 & 10.2 & 16.2 & 28.1 & 13.2 & 14.9 & 0.0 & 3.8 & 382 & 650 & 115 \\
\hline \multirow[t]{2}{*}{ OIR } & 1998 & 10.6 & 16.2 & 24 & 11.3 & 12.7 & 1.6 & 0.0 & 370 & 677 & 250 \\
\hline & 1999 & 12.8 & 16.2 & 22.1 & 10.0 & 12.1 & 2.5 & 0.0 & 369 & 684 & 250 \\
\hline osw & 1998 & 14.2 & 17.9 & 18.9 & 8.8 & 10.1 & 2.3 & 4.5 & 402 & 704 & 88 \\
\hline \multirow[t]{2}{*}{ OUK } & 1998 & 13.5 & 16.1 & 20.4 & 9.2 & 11.2 & 1.3 & 1.3 & 377 & 677 & 110 \\
\hline & 1999 & 12.0 & 16.1 & 20.8 & 9.7 & 11.1 & 1.1 & 1.4 & 398 & 690 & 250 \\
\hline Average & - & 14.6 & 16.4 & 23.8 & 10.8 & 13.0 & 1.4 & - & 379 & 624 & 180 \\
\hline
\end{tabular}

[a] Locations were defined in Table 1.

[b] Plants were located under rain-out shelter.

[c] Values not reported. Crops were irrigated to maintain soil moisture content above $75 \%$ of field capacity.

simulations for a given dataset.

\section{Results}

\subsection{Yield predictions across locations for ambient $\mathrm{CO}_{2}$ concentration}

Observed Ca yields across all locations varied from 8.5 to $22.7 \mathrm{Mg}$ $\mathrm{ha}^{-1}$ (Fig. 1) and models were challenged to replicate this range using a single calibration set. Percent EOS-yield error averaged $26.5 \%$ across all models and locations (Table 4). Slopes of 1:1 plots between observed and simulated EOS-yields were above unity for eight of the 10 models (Table 4), and MME mean slope was 1.06, indicating a small trend towards under-estimating yields (Fig. 2). This under-prediction was associated with locations where EOS-yields exceeded $15 \mathrm{Mg} \mathrm{ha}^{-1}$. Conversely, over-predictions occurred when the observed yields were less than $10 \mathrm{Mg} \mathrm{ha}^{-1}$. Models with slopes greater than unity had MBE less than zero and those with slopes less than one showed positive bias. Seven out of ten models had negative MBE values averaging $-0.93 \mathrm{Mg}$ $\mathrm{ha}^{-1}$, lending support to the overall bias towards under-prediction. There was considerable variation among models for this trend, however, as MBE ranged between a high of $0.57 \mathrm{Mg} \mathrm{ha}^{-1}$ and a low of -4.6 (Fig. 3).

Models that alternated between over- and under- prediction of yields among individual locations were likely to have a value of MBE close to zero. However, a more negative or positive MBE was not necessarily associated with more accurate predictions. For example, M1, M3, M4, and M9 had MBE values of $-0.6 \mathrm{Mg} \mathrm{ha}^{-1}$ or lower, but also had more accurate Perr results (Table 4). Root means square error (RMSE) and RMSRE results were similar in response to Perr, since most datasets other than OUK and FIT had only two or three time-series measurements for yield. These metrics varied broadly among models, with RMSRE ranging from 18 to $59 \%$ (Fig. 3). The index of agreement also followed similar trends as RMSE or RMSRE (Table 4). Noteworthy is that the MME mean for IA was 0.51 , which indicates that even after calibration, models on average were only explaining $50 \%$ of the locational variability of the observed yield.

\subsection{Yield predictions across locations for elevated $\mathrm{CO}_{2}$ concentration}

The MME mean Perr across all models for EOS-yield was similar to Ca calibration results, averaging $27.2 \%$ (Table 4 ). Accuracy varied broadly across locations (Fig. 1), and variation among individual model Perr ranged between a low of $12.5 \%$ and a high of $51 \%$. Slopes were higher than unity for four out of 10 models, suggesting that there was less tendency to under-predict EOS-yields as compared with $\mathrm{Ca}$ data (Table 4). However, sets with high EOS-yields were still under-predicted (Fig. 4). The mean MME mean bias error was about half that of Ca results $\left(-0.55\right.$ compared with $\left.-0.93 \mathrm{Mg} \mathrm{ha}^{-1}\right)$, but there was more variation among individual models (Fig. 3).

RMSE was higher than the Ca results for all models, with an average $34 \%$ increase (Table 4). However, this increase was roughly proportional to the larger EOS-yields observed in response to increasing $\mathrm{CO}_{2}$. When expressed as RMSRE, the errors for individual models and MME mean between the two $\mathrm{CO}_{2}$ levels were similar (Fig. 3). The index of agreement declined slightly from 0.51 to 0.47 , although there were individual models whose values were closer to the ideal score of 1 .

\subsection{Influence of location}

More accurate calibration results were generally associated with more accurate Ce responses. For example, the lowest MME Perr values from Ca datasets were associated at OBE, OIR, and OSW locations, which also remained among the lowest errors for Ce predictions (Table 5). Conversely, locations with largest errors during calibration, such as FIT and OUK, exhibited similar inaccuracies for Ce responses. A modeling analysis by Wolf and Van Oijen (2002) observed similar challenges when using the CHIP dataset for potato model assessment possibly associated with limitations due to inadequate plot size, edge effects, and OTC artifacts. The disparity in model accuracy for certain locations may also be associated with large differences in observed annual yields. For example, differences for $\mathrm{Ca}$ and Ce data at FGE were 5.8 and $6.8 \mathrm{Mg}$ $\mathrm{ha}^{-1}, 6.9$ and $8.1 \mathrm{Mg} \mathrm{ha}^{-1}$ at OGE, and 13 and $22 \mathrm{Mg} \mathrm{ha}^{-1}$ at OUK. CHIP protocols changed between 1998 and 1999, using larger seed-piece size and decreased planting density. However, this change does not explain the considerably closer annual variation among other locations. An increase in daily solar radiation intensity between 1998 and 1999 of 2.7 MJ $\mathrm{m}^{-2} \mathrm{~d}^{-1}$ was observed for the FGE location which may have explained the higher yields (Table 2), but there were little differences in annual climate conditions for OGE and OUK. Water and nitrogen management were also similar for both years at these locations, except FGE 1999 year received about $1 \mathrm{~mm} \mathrm{~d}^{-1}$ more of total rainfall and irrigation while the OUK 1999 year had more than double the fertilizer rate (Table 2). Authors did not report either water or nitrogen stress at the prior year at these locations, however. FGE and OGE sites were also pot studies placed under moveable rainout shelters (Table 1) which may have exerted an additional influence on light quality and air, soil and 
Table 3

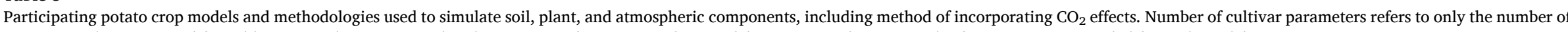
parameters that were used for calibration in the current study. The primary reference regarding model structure and operational information was provided for each model.

\begin{tabular}{|c|c|c|c|c|c|c|c|c|c|c|c|c|c|c|}
\hline Model & $\begin{array}{l}\text { Leaf area } \backslash \\
\text { Light } \\
\text { interception }{ }^{\text {a }}\end{array}$ & $\begin{array}{l}\text { Light } \\
\text { utilization }{ }^{b}\end{array}$ & $\begin{array}{l}\text { Yield } \\
\text { formation }^{c}\end{array}$ & $\begin{array}{l}\text { Crop } \\
\text { phenology }\end{array}$ & $\begin{array}{l}\text { Root } \\
\text { distribution }\end{array}$ & $\begin{array}{l}\text { Environmental } \\
\text { stresses }^{f}\end{array}$ & $\begin{array}{l}\text { Water } \\
\text { stress }{ }^{g}\end{array}$ & $\begin{array}{l}\text { Heat } \\
\text { stress }{ }^{h}\end{array}$ & $\begin{array}{l}\text { Water } \\
\text { dynamics }{ }^{i}\end{array}$ & $E T^{j}$ & $\begin{array}{l}\text { Soil CN- } \\
\text { model }^{\mathrm{k}}\end{array}$ & $\begin{array}{l}\mathrm{CO}_{2} \\
\text { effects }{ }^{1}\end{array}$ & $\begin{array}{l}\text { \# of cultivar } \\
\text { parameters }\end{array}$ & Reference \\
\hline AQUACROP V6.0 & $\mathrm{s}$ & $\mathrm{TE}$ & $\mathrm{HI}$ & $\mathrm{T}$ & LIN & $\mathrm{W}, \mathrm{A}, \mathrm{H}, \mathrm{O}$ & $\mathrm{s}$ & $\mathrm{R}$ & $\mathrm{C}, \mathrm{RO}$ & $\begin{array}{l}\text { P, PM, } \\
\text { PT,TW, } \\
\text { MAK, } \\
\text { HAR,SW }\end{array}$ & - & $\mathrm{TE}$ & 10 & $\begin{array}{l}\text { Steduto et al. } \\
\text { (2009) }\end{array}$ \\
\hline CROPSYST V4 & $\mathrm{s}$ & TE*, RUE & HI, B & $\mathrm{T}, \mathrm{DL}$ & LIN & $\mathrm{W}, \mathrm{N}$ & $\mathrm{E}$ & & $\mathrm{C}, \mathrm{R}$ & PM, PT & $\mathrm{N}, \mathrm{P}(4)$ & $\begin{array}{l}\text { TE*, } \\
\text { RUE }\end{array}$ & 13 & $\begin{array}{l}\text { Stockle et al. } \\
(2003)\end{array}$ \\
\hline $\begin{array}{l}\text { DSSATv4.7 CSM- } \\
\text { SUBSTOR_Potato }\end{array}$ & $\mathrm{s}$ & RUE & Tn, Prt & T,DL, O & CA, O & $\mathrm{W}, \mathrm{N}, \mathrm{A}$ & $\mathrm{E}$ & $\mathrm{V}, \mathrm{R}$ & C & PM,PT & $\begin{array}{l}\mathrm{CN}, \mathrm{P} \\
\text { (3) }\end{array}$ & $\begin{array}{l}\text { PT, } \\
\text { RUE }\end{array}$ & 5 & $\begin{array}{l}\text { Hoogenboom } \\
\text { et al. (2019) }\end{array}$ \\
\hline EXPERTN - SPASS & D & P-R & Prt & $\mathrm{T}, \mathrm{DL}$ & $\mathrm{O}$ & $\mathrm{W}, \mathrm{N}, \mathrm{A}, \mathrm{H}$ & $\mathrm{E}, \mathrm{S}$ & $\mathrm{v}$ & $\mathrm{R}$ & PM & $\begin{array}{l}\mathrm{CN}, \mathrm{P} \\
\text { (3) }\end{array}$ & RUE & 6 & $\begin{array}{l}\text { Stenger et al. } \\
\text { (1999) }\end{array}$ \\
\hline EXPERTN -GECROS & D & P-R & Tn, Prt & $\mathrm{T}, \mathrm{DL}$ & LIN & $\mathrm{W}, \mathrm{N}, \mathrm{H}$ & $\mathrm{E}$ & $\mathrm{v}$ & $\mathrm{R}$ & PM & $\begin{array}{l}\text { CN, P } \\
\text { (3) }\end{array}$ & F,T, PT & 6 & $\begin{array}{l}\text { Stenger et al. } \\
\text { (1999) }\end{array}$ \\
\hline LINTUL V4 & $\mathrm{s}$ & RUE & Prt & T, DL & LIN & W,A N & $\mathrm{s}$ & V & C & $\mathrm{P}$ & - & RUE & 10 & $\begin{array}{l}\text { Shibu et al. } \\
\text { (2010) }\end{array}$ \\
\hline MONICA V1.0 & $\mathrm{s}$ & $\mathrm{P}-\mathrm{R}$ & Prt & T,DL, V,O & EXP & $\mathrm{W}, \mathrm{N}, \mathrm{A}, \mathrm{H}$ & E, $S$ & V & C & PM & $\begin{array}{l}\mathrm{CN}, \mathrm{P} \\
\text { (6), B }\end{array}$ & PT, F & 12 & $\begin{array}{l}\text { Nendel et al. } \\
\text { (2011) }\end{array}$ \\
\hline SOLANUM & $\mathrm{s}$ & RUE & Prt & $\mathrm{T}$ & NR & $\mathrm{W}, \mathrm{H}$ & E, $S$ & $\mathrm{~V}, \mathrm{R}$ & C & PM & - & RUE & 8 & $\begin{array}{l}\text { Harahagazwe } \\
\text { et al. (2018) }\end{array}$ \\
\hline SPUDSIM v.2.0 & D & $\mathrm{P}-\mathrm{R}$ & Prt & T,DL, O & $\mathrm{CA}, \mathrm{O}$ & W,N, H & $\mathrm{E}, \mathrm{S}$ & $\mathrm{V}, \mathrm{R}$ & $\mathrm{R}$ & PM, PT, O & $\begin{array}{l}\mathrm{CN}, \mathrm{P} \\
\text { (2) }\end{array}$ & $\mathrm{F}, \mathrm{T}, \mathrm{LF}$ & 7 & $\begin{array}{l}\text { Fleisher et al. } \\
\text { (2010b) }\end{array}$ \\
\hline TIPSTAR & $\mathrm{s}$ & RUE & Tn, Prt & $\mathrm{T}$ & EXP & $\mathrm{W}, \mathrm{N}, \mathrm{A}$ & $\mathrm{E}, \mathrm{S}$ & & C & MAK & $\mathrm{CN}$ & RUE & 4 & Jansen (2008) \\
\hline
\end{tabular}

${ }^{\text {a }}$ Leaf area development and light interception: S, simple approach (e.g. LAI); D, detailed approach (e.g. canopy layers).

b Light utilization or biomass growth: RUE radiation use efficiency approach; P-R, gross photosynthesis - respiration; TE, transpiration efficiency biomass growth.

c Yield formation depending on: HI, fixed harvest index; B, total (above-ground) biomass; Tn, number of tuber or tuber growth rate; Prt, partitioning during reproductive stages.

d Crop phenology is a function of: T, temperature; DL, photoperiod (day length); $\mathrm{O}$, other water/nutrient stress effects considered.

e Root distribution over depth: LIN, linear; EXP, exponential; SIG, sigmoidal; CA, carbon allocation; NR, no roots-just soil depth zone; O, other approaches.

${ }^{\mathrm{f}}$ Stresses involved: W, water stress; N, nitrogen stress; A, aeration deficit stress; H, heat stress; O, other stresses.

$\mathrm{g}$ Type of water stress: E, actual to potential evapotranspiration ratio; S, soil available water in root zone.

${ }^{h}$ Type of heat stress: Stress applied to V, vegetative organ (source); R, reproductive organ (sink).

${ }^{i}$ Water dynamics: C, "Tipping bucket" capacity approach; R, Richards approach.

${ }^{j}$ Evapotranspiration: P, Penman; PM, Penman-Monteith; PT, Priestley-Taylor; TW, Turc-Wendling; MAK, Makkink; HAR, Hargreaves; SW, Shuttleworth and Wallace (resistive model).

${ }^{k}$ Soil CN-model: CN, CN model; N, N model; P(x), x number of organic matter pools; B, microbial biomass pool.

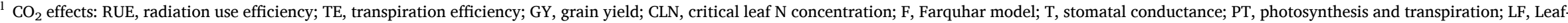
level photosynthesis-rubisco o on $\mathrm{QE}$ and Amax.

* TE methodology was disabled for this study such that only RUE was used for both light utilization and $\mathrm{CO}_{2}$ response. 


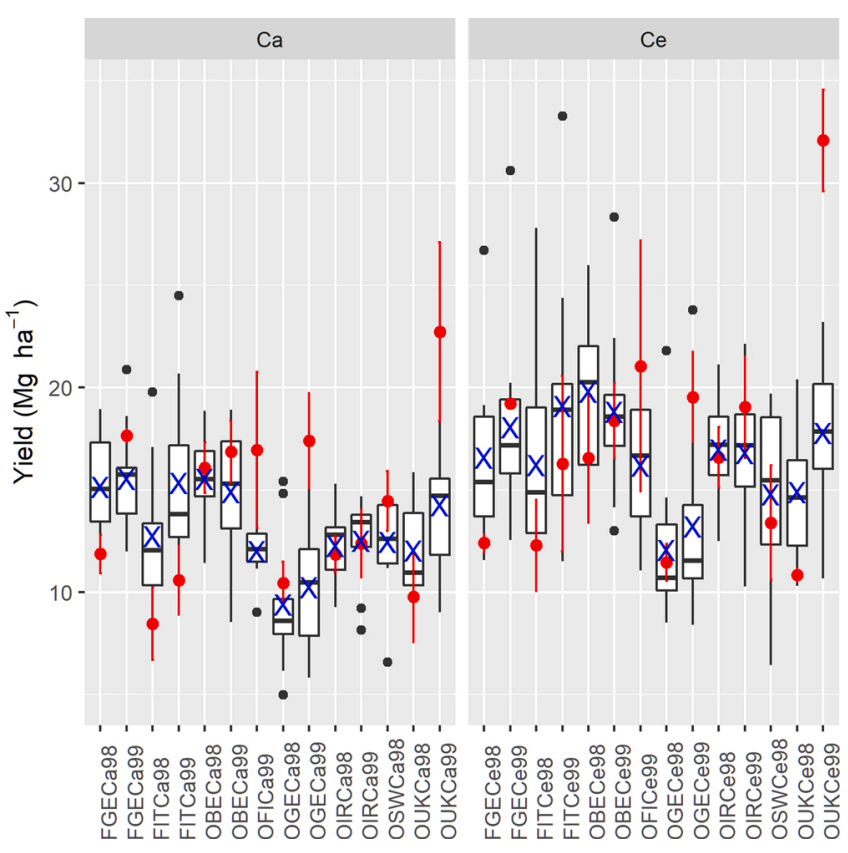

Fig. 1. Variation in simulated end-of-season potato tuber yield (dry mass basis) among potato models $(n=10)$ versus site $\mathrm{x}$ year combinations under ambient (Ca, left column) and elevated $\mathrm{CO}_{2}$ (Ce, right column) as identified in Table 1. Observed means ( $\mathrm{n}=6$ for OSW, 2 for FGE and OGE, and 3 for all other locations) are shown as red dots along with standard deviations, median of model simulations shown as black horizontal bars, average of model simulations shown as ' $\mathrm{X}$ ', and model outlier points indicated as black dots.

leaf temperatures not captured by the models or measured by the experimental data. The use of pots may also restrict root growth and affect yields as well as posing challenges in estimating planting density as area per plant is based on the spread of the plant for light capture and not necessarily pot size (e.g. Poorter et al., 2012).

The FIT location was associated with the highest model ensemble errors, and the calibration Ca data was over-predicted by $45-50 \%$ (Fig. 1, Table 5). Both years were characterized by higher daily solar radiation, maximum temperatures, and shorter photoperiod prior to tuber initiation than other locations $\left(+6 \mathrm{MJ} \mathrm{m}^{-2} \mathrm{~d}^{-1},+3.9^{\circ} \mathrm{C}\right.$, and -1.2 $\mathrm{h}$ respectively, Table 2 ). Both years were also irrigated and had similar fertilizer amounts. The observed yield was also lower than those measured at other locations (Table 5, Fig. 1). Wolf and Van Oijen (2003) indicated that the pre-planting procedures at the FIT location resulted in a relatively low leaf area index (LAI). The LPOTCO model from their study was only able to replicate the yield data when the model used fixed LAI measurements observed from the data set. This may have explained the very large errors for this location in our study. Assessment of site-specific model performance also indicated that FIT, more than any other location, was strongly skewed by outlying model results (Fig. 5). At this location, model M2 exhibited particularly high errors for $\mathrm{Ca}$ and Ce datasets, and M7 and M8 showed high errors for Ca datasets (Fig. 5). Removing these models reduced the mean MME Perr at the FIT location to less than $35 \%$ for $\mathrm{Ca}$ and $25 \%$ for Ce datasets (not shown).

Agreement among models varied considerably (Table 5). Under Ca sets, CVs (expressed as a fraction) ranged from 0.16 to 0.36 and averaged 0.22 . Although the highest CVs were associated with both years at FIT (0.26 and 0.29) and OGE (0.33 and 0.36) Ca datasets, a consistent relationship between Perr and CV was not observed at other locations. This is because lower CVs imply more precision among models in the ensemble, but that agreement does not necessarily result in a higher accuracy if most models are still under- or over-estimating the observed yields. The CV increased slightly to an average of 0.26 for Ce results. The highest variation among models was still observed at FIT and OGE with
Table 4

Individual model metrics for EOS-yield predictions across all locations. Metrics include index of agreement (IA), percent error (Perr), mean bias error (MBE), root mean square error (RMSE), root mean square relative error (RMSRE), slope of the 1:1 plot between observed and simulated values, and correlation coefficient from this relationship $\left(R^{2}\right)^{[a]}$. Negative values for MBE indicate underpredictions.

\begin{tabular}{|c|c|c|c|c|c|c|c|}
\hline \multirow{3}{*}{ Model } & \multicolumn{7}{|l|}{ Metric } \\
\hline & \multirow[t]{2}{*}{ IA } & \multirow{2}{*}{$\begin{array}{l}\text { Perr } \\
\%\end{array}$} & \multirow{2}{*}{$\begin{array}{l}\mathrm{MBE} \\
\mathrm{Mg} \mathrm{ha}^{-1}\end{array}$} & \multirow[t]{2}{*}{ RMSE } & \multirow{2}{*}{$\begin{array}{l}\text { RMSRE } \\
\%\end{array}$} & \multirow{2}{*}{$\begin{array}{l}\text { Slope } \\
\mathrm{Mg} \mathrm{Obs} \mathrm{Mg}_{\mathrm{Sim}^{-1}}\end{array}$} & \multirow[t]{2}{*}{$\mathrm{R}^{2}$} \\
\hline & & & & & & & \\
\hline \multicolumn{8}{|c|}{ Ambient $\mathrm{CO}_{2}$ Concentration } \\
\hline 1 & 0.65 & 19.5 & -1.59 & 3.48 & 21 & 1.13 & 0.96 \\
\hline 2 & 0.38 & 41.1 & 0.05 & 7.05 & 59 & 0.85 & 0.79 \\
\hline 3 & 0.83 & 15.6 & -0.93 & 2.76 & 18 & 1.07 & 0.97 \\
\hline 4 & 0.59 & 19.8 & -1.0 & 3.59 & 24 & 1.07 & 0.94 \\
\hline 5 & 0.38 & 25.4 & -0.27 & 4.24 & 31 & 1.00 & 0.92 \\
\hline 6 & 0.42 & 32.0 & 0.08 & 5.09 & 41 & 0.94 & 0.88 \\
\hline 7 & 0.39 & 35.6 & -4.61 & 6.68 & 40 & 1.38 & 0.86 \\
\hline 8 & 0.35 & 32.0 & 0.57 & 5.25 & 43 & 0.91 & 0.88 \\
\hline 9 & 0.75 & 17.2 & -0.66 & 3.24 & 21 & 1.04 & 0.95 \\
\hline 10 & 0.38 & 26.7 & -0.93 & 4.51 & 31 & 1.04 & 0.91 \\
\hline $\begin{array}{l}\text { MME } \\
\text { mean }\end{array}$ & 0.51 & 26.5 & -0.93 & 4.58 & 33 & 1.06 & 0.93 \\
\hline $\begin{array}{l}\text { MME } \\
\text { median }\end{array}$ & 0.41 & 26.5 & -0.80 & 4.38 & 31 & 1.04 & \\
\hline \multicolumn{8}{|c|}{ Elevated $\mathrm{CO}_{2}$ Concentration } \\
\hline 1 & 0.85 & 14.3 & 0.61 & 3.33 & 17 & 0.97 & 0.97 \\
\hline 2 & 0.25 & 51.0 & 4.60 & 9.95 & 64 & 0.71 & 0.82 \\
\hline 3 & 0.79 & 12.5 & -2.36 & 3.88 & 16 & 1.18 & 0.97 \\
\hline 4 & 0.42 & 25.4 & -3.16 & 6.18 & 28 & 1.21 & 0.91 \\
\hline 5 & 0.42 & 31.2 & 1.99 & 5.75 & 38 & 0.89 & 0.91 \\
\hline 6 & 0.54 & 26.3 & -0.56 & 5.84 & 35 & 0.99 & 0.89 \\
\hline 7 & 0.41 & 29.6 & -5.23 & 8.03 & 36 & 1.36 & 0.86 \\
\hline 8 & 0.27 & 29.6 & 0.03 & 6.36 & 35 & 0.96 & 0.88 \\
\hline 9 & 0.55 & 21.6 & -2.73 & 5.78 & 27 & 1.16 & 0.91 \\
\hline 10 & 0.21 & 30.5 & 1.34 & 6.31 & 39 & 0.90 & 0.89 \\
\hline $\begin{array}{l}\text { MME } \\
\text { mean }\end{array}$ & 0.47 & 27.2 & -0.55 & 6.14 & 34 & 1.03 & 0.92 \\
\hline $\begin{array}{l}\text { MME } \\
\text { median }\end{array}$ & 0.42 & 28.0 & -0.27 & 6.01 & 35 & 0.98 & \\
\hline
\end{tabular}

[a] Note that linear models with no intercept (as in this case) require use of an adjusted formula to calculate $\mathrm{R}^{2}$. This is not considered to be as useful a metric as would be obtained from the full linear model (Alexander et al., 2015).

an average of 0.32 and 0.35 across years. As with the Ca results, aside from the FIT location, most of the CV was not associated with outlier predictions from models.

Observed EOS-yields increased by $21.9 \%$ (or about $13 \mathrm{~kg} \mathrm{ppm}^{-1}$ ) in response the increased $\mathrm{CO}_{2}$ concentration across all locations and years (Table 5). The MME mean was $26.8 \%\left(16 \mathrm{~kg} \mathrm{ppm}^{-1}\right)$, suggesting that the simulated relative yield increase was accurate. However, there was a broad range of under- and over-prediction of the $\mathrm{CO}_{2}$ enrichment effect primarily associated with FIT, OBE, and OGE locations. Differences in predicted and observed relative yield increase across both years were about $20 \%,-22 \%$, and $-22 \%$ respectively, for these datasets. Responses at FIT were under-predicted by 19 or $31 \%$ depending on year and were attributed to over-prediction of yield for Ca datasets and under-prediction for Ce (Fig. 1). Conversely, errors at OBE and OGE (Table 5) were associated with under-prediction of $\mathrm{Ca}$ and overprediction of Ce yield. Observed OSW Ce responses were unique in showing a decline in yield to the higher $\mathrm{CO}_{2}$ level, a response that no model replicated.

\subsection{Individual and group rankings}

Performance of individual models was evaluated using all six metrics (IA, Perr, MBE, RMSE, RMSRE, and slope) from Table 4 and based on the frequency in which a given model was ranked in the top or bottom five 


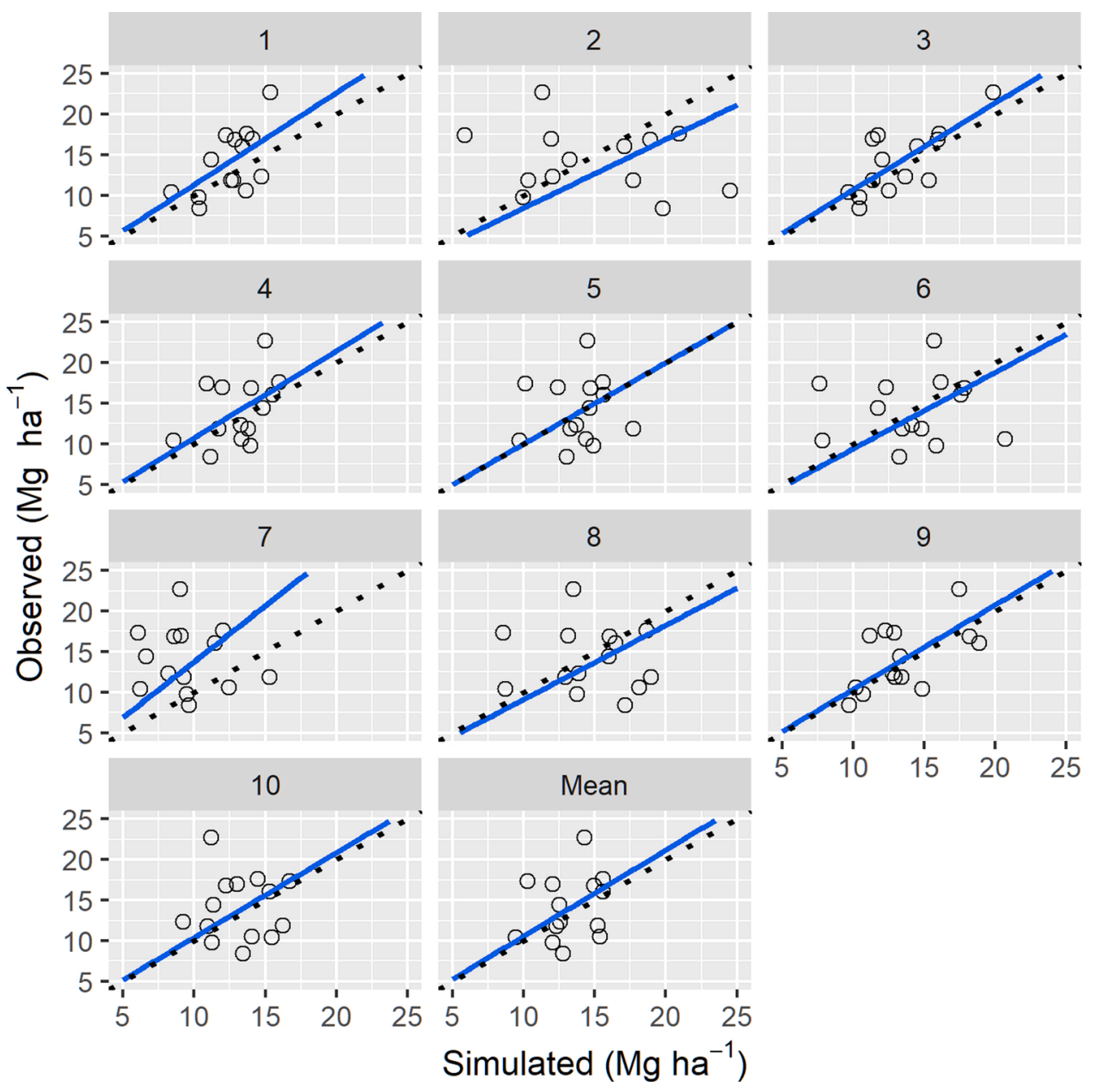

Fig. 2. Observed versus simulated EOS-yields per model (numbered 1 through 10) and multi-model ensemble mean across all locations for ambient $\mathrm{CO}_{2}$ datasets. The perfect 1:1 line (with slope of unity) shown in black dashed line, actual regression line shown in blue. Slopes were provided in Table 4.

for $\mathrm{Ca}$ and Ce simulated yield results. No individual model consistently outperformed the MME median or mean for all $\mathrm{Ca}$ and Ce datasets. However, there were models that more consistently ranked ahead of MME values than other models for either $\mathrm{Ca}$ or Ce data. Models that performed collectively better across all metrics for calibration results under Ca did perform better for Ce predictions (Fig. 6). For example, Models M1, M3, M4, M5, and M9 were most frequently in the top five of models for each metric four or more times for Ca calibration sets. For Ce predictions, models M1, M3, M6, and M9 were most frequently ranked in the top five four or more times. In this case, models M1 and M6 improved slightly from Ca results, from four to six and three to five respectively, while models M5 and M4 dropped slightly. Models that did not perform as well for calibration to Ca data, including M2, M7, and M10, stayed towards the bottom set for Ce predictions, and were frequently below MME mean and median. Across all locations, roughly three out of five models (or $58 \%$ of the time) that were among the lowest Perr values for calibration exhibited the same behavior for Ce predictions (Table 6).

Performance of models grouped according to the mechanism by which they incorporated $\mathrm{CO}_{2}$ response was roughly similar (Table 7). Under Ca datasets, the TE-based approach exhibited the best IA and Perr metrics but had the highest slope and RMSRE. The LF group showed the best RMSRE but the most bias, and the RUE model group exhibited the least bias and best slope but worse metrics for IA, Perr, and RMSE. Out of the six metrics, the TE model was better than MME twice, LF models three times, and RUE models once.

Predictions for Ce datasets gave similar results. The TE model was better than the MME for all metrics except MBE. The LF models outperformed the MME for three metrics, but RUE did not show better values than MME for any metric. The relative response to elevated $\mathrm{CO}_{2}$ also varied considerably among model structure groups (Table 7) from a low of $13 \%$ for LF models to a high $41 \%$ for the TE model, with RUE models at $31 \%$. Given the observed response was $22 \%$ (Table 5), both RUE and LF approaches would be considered more accurate for this relative response. It bears strong emphasis that the TE group was only composed of a single model and thus the present comparisons are not statistically relevant. Whether these results were due to model structure or calibration methodology cannot be determined.

\section{Discussion}

Much of the literature that explores projected climate impacts on plant production uses crop models calibrated with Ca data (e.g. Ahmad et al., 2020; Chen et al., 2020; Resop et al., 2016). This implicitly assumes that models contain sufficient knowledge, and/or have been rigorously evaluated in prior research, such that extrapolations to rising $\mathrm{CO}_{2}$ levels will be accurate. The present study showed that potato models had difficulties capturing the absolute magnitude of Ce yield response when using this approach. Mean MME Perr were lower than a somewhat arbitrary threshold of $15 \%$ for only six out of fourteen datasets (Table 5), and models generally under-predicted Ce yields at several locations (Fig. 1). The relative response to elevated $\mathrm{CO}_{2}$ was more accurate than absolute yield predictions, with less than a $6 \%$ difference (less than $3.3 \mathrm{~kg} \mathrm{ppm}^{-1}$ ) between predicted and observed 

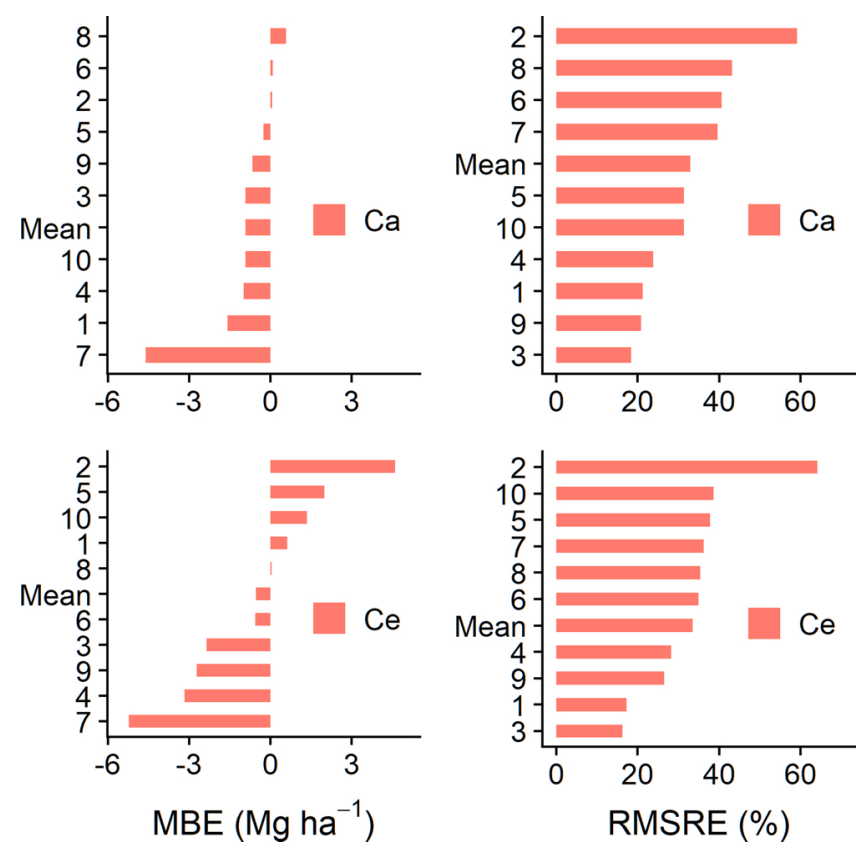

Fig. 3. Mean bias error (MBE, left) and root mean square relative error (RMSRE, right) for end-of-season yield predictions across all locations for individual models (Models 1 through 10) and multi-model ensemble (mean) for Ca (top) and Ce (bottom) datasets.

response (Table 5). However, averaging across locations obscures large variations in errors among individual locations and years. These results demonstrated that using the current set of potato models in an ensemble to extrapolate rising $\mathrm{CO}_{2}$ effects without including calibration data for Ce responses is likely to under-estimate absolute yield response for the individual locations in the study region. Conversely, relative responses to $\mathrm{CO}_{2}$ averaged over the region of interest were accurate.

These results differ from those of similar MME studies with cereal crops such as Durand et al. (2018), in which nearly half of models in a 21 maize model inter-comparison study were able to match elevated $\mathrm{CO}_{2}$ observed grain yield in FACE systems with errors less than $1 \mathrm{Mg} \mathrm{ha}^{-1}$, or about $10 \%$. Ewert et al. (2002) also reported good agreement between predicted and observed Ce wheat grain yield response for three models using FACE system data. These authors found unsatisfactory results with respect to Ce responses for OTC experimental data on wheat. In another wheat study, Van Oijen and Ewert (1999) showed that two models were able to replicate Ce responses from OTC chambers across Europe with less than $10 \%$ error, but cited challenges replicating annual variation. In a rice MME, Hasegawa et al. (2017) observed less than 3\% error between simulated and predicted relative grain yield response to Ce. Still, on an individual model by treatment basis, errors varied between -1 to $50 \%$, an extreme range that was quite similar to our results (Table 5 ). In these latter two studies, modelers appeared to access $\mathrm{Ca}$ and Ce datasets for calibration purposes, which confounds any direct question regarding the capability of models to simulate Ce responses when calibrated with only Ca data.

The potato models in this research incorporate well-established subroutines and methodologies for direct and indirect response to $\mathrm{CO}_{2}$ enrichment (Table 3), most of which have been evaluated on an individual basis (e.g. Fleisher et al., 2010b; Stockle et al., 2003). However, as is a common situation for other crop models, published studies that compare responses for growth, yield, and development over an entire growing season with elevated $\mathrm{CO}_{2}$ are scarce. In that sense, the present study is an important step forward towards providing a more rigorous evaluation for whole model responses to climate change factors. Some individual models generally performed better than others for Ce responses, including M1, M3, M6, and M9 (Table 6, Fig. 6). These models outperformed MME median or mean for more than half of the Ce datasets, which contrasts with other studies which concluded that MME results were more likely to out-perform all individual models when considering all treatments evaluated (Asseng et al., 2013; Bassu et al., 2014; Li et al., 2015). However, we are not aware of any studies that specifically evaluated individual versus MME responses against Ce data and reached a similar result. Still, since the best models only outperformed MME results for a maximum of nine out of 14 Ce sites (Table 6), more confidence can be obtained when using an MME approach.

In two different rice MME studies, Hasegawa et al. (2017) and Li et al. (2015) observed that RUE based models tended to vary more widely for yield predictions than biochemically based leaf-level models, but no differences in accuracy due to model structure were observed. Our results show a slightly worse performance for RUE-based models, as compared to LF or TE approaches for most metrics (Table 7). However, model sample sizes were insufficient and unbalanced, as needed for an accurate measure of statistical significance, with six models grouped under RUE approaches, three for leaf-level, and only one for TE (Table 3). The four top performing models were representative of all three model structure groups (RUE, LF and TE), with two of the models associated with RUE approaches which may have been consistent with the higher number of models in this grouping. No effort was made to remove location outliers from the analysis, although it was apparent that performance of individual models across all datasets could be strongly skewed by just one of the seven locations. For example, M2, part of the RUE group, had some of the higher percent errors when averaged across all locations, but most of which were attributed to FIT. If one were to remove this one location, M2 Perr scores were reduced such that the model was close to MME means for Ca and Ce sets.

The similarity in CV between MME yield predictions for $\mathrm{Ca}$ and $\mathrm{Ce}$ data was reported for other studies (e.g. Asseng et al., 2013; Bassu et al., 2014; Fleisher et al., 2017; Li et al., 2015). Asseng et al. (2013) suggested this was because elevated $\mathrm{CO}_{2}$ influences fewer processes as compared to other factors (such as temperature). The same experimental data sources were also likely used by most crop modelers for testing and improving model responses given the limited availability of elevated $\mathrm{CO}_{2}$ field data, and this may have led to a convergence in yield predictions regardless of model structure. Model variability for $\mathrm{Ca}$ or $\mathrm{Ce}$ predictions across all locations was about $8 \%$ higher than that reported in the Fleisher et al. (2017) potato MME study. Results from that study were aggregated from only four treatment locations at which modelers developed a separate set of calibration values per site such that variation would be expected to be lower. In the present case, the increase in uncertainty did not necessarily correlate with the accuracy of MME mean (or median) response, especially for Ce results (Table 5). This concurs with Carter (2013) and Asseng et al. (2013) who indicated that higher model agreement within an MME does not necessarily imply accuracy. Results suggest that it may be preferable to include only the most accurate performing models in a MME, or weight model contributions differently according to their track record of accuracy, as discussed with different nuances in the climate modeling community (Knutti et al., 2010). For example, removing M2 and M7 from the MME reduced Perr from 27.2 to $21.1 \%$ across all locations for Ce datasets. However, there is no evidence to suggest models that are the most, or least, accurate in one study such as this one would remain so in other evaluations, and thus significantly more testing with additional datasets would be needed to implement this concept for the potato crop modeling community.

Hasegawa et al. (2017) noted that variability among rice models to elevated $\mathrm{CO}_{2}$ responses was primarily associated with leaf area predictions and not due to differences in methodology regarding direct $\mathrm{CO}_{2}$ response. Models that over-predicted yields in their study generally did so for all treatments, suggesting that such biases were not random and could be corrected for. We did not observe this relationship where sufficient time-series experimental data was available. Models that over-predicted yield did not always have higher values for total above 


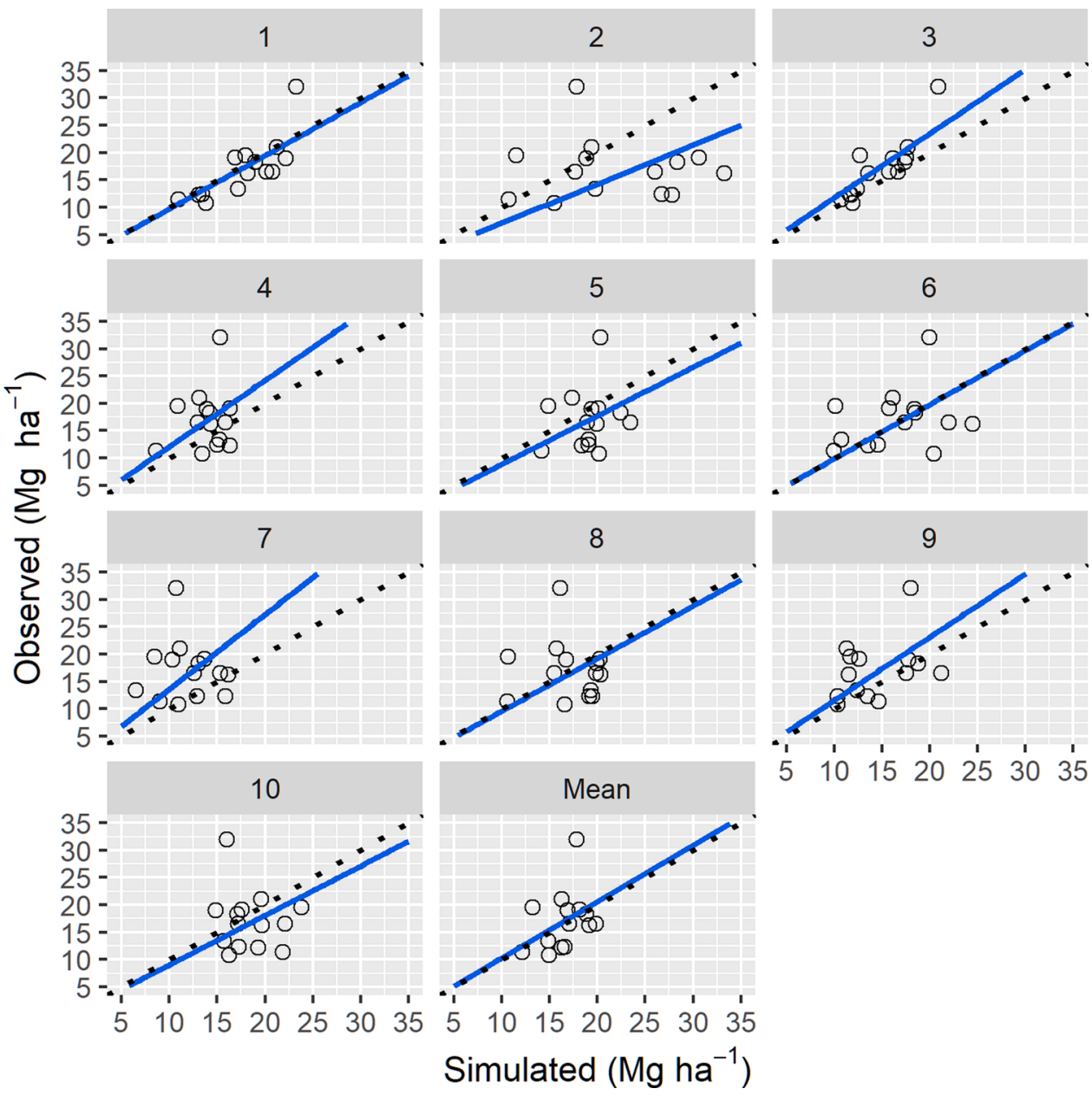

Fig. 4. Observed versus simulated EOS-yields per each model (numbered 1 through 10) and multi-model ensemble mean across all locations for elevated $\mathrm{CO}_{2}$ data sets. The perfect 1:1 line (with slope of unity) shown in black dashed line, actual regression line shown in blue. Slopes were provided in Table 4.

Table 5

Locational differences with respect to observed yield (standard deviations shown in parenthesis), Multi-model ensemble mean percent error (MME Perr), and coefficient of variation $(\mathrm{CV})$. Relative yield increase to elevated $\mathrm{CO}_{2}$ was shown as indicated for observed and simulated datasets. Asterisks indicate locations that were under-predicted by the mean of all models.

\begin{tabular}{|c|c|c|c|c|c|c|c|c|c|c|}
\hline \multirow[t]{2}{*}{ Dataset } & \multirow{2}{*}{$\begin{array}{l}\text { Observed Yield }\left(\mathrm{Mg} \mathrm{ha}^{-1}\right) \\
\text { Ambient }\end{array}$} & \multirow[t]{2}{*}{ MME Perr } & \multirow[t]{2}{*}{$\mathrm{CV}$} & \multirow{2}{*}{$\begin{array}{l}\text { Observed Yield }\left(\mathrm{Mg} \mathrm{ha}^{-1}\right) \\
\text { Elevated }\end{array}$} & \multirow[t]{2}{*}{ MME Perr } & \multirow[t]{2}{*}{$\mathrm{CV}$} & \multicolumn{2}{|c|}{ Observed Ce/Ca Response } & \multicolumn{2}{|c|}{ Simulated Ce/Ca Response } \\
\hline & & & & & & & $\%$ & $\left(\mathrm{~kg} \mathrm{ha}^{-1} \mathrm{ppm}^{-1}\right)$ & $\%$ & $\left(\mathrm{~kg} \mathrm{ha}^{-1} \mathrm{ppm}^{-1}\right)$ \\
\hline FGE98 & $11.9(0.9)$ & 27.5 & 0.16 & $12.4(0.4)$ & 33.7 & 0.26 & 4.2 & 15.2 & 8.5 & 42.7 \\
\hline FGE99 & $17.7(0.3)$ & $12.2^{*}$ & 0.18 & $19.2(0.2)$ & $5.8^{*}$ & 0.28 & 8.5 & 13.3 & 15.4 & 22.5 \\
\hline FIT98 & $8.5(1.8)$ & 50.1 & 0.26 & $12.3(2.2)$ & $32.0^{*}$ & 0.32 & 44.7 & 20.4 & 26.5 & 18.7 \\
\hline FIT99 & $10.6(1.7)$ & 45.0 & 0.29 & $16.3(4.3)$ & $17.2 *$ & 0.33 & 53.8 & 30.7 & 23.7 & 20.1 \\
\hline OBE98 & $16.1(1.2)$ & $3.4^{*}$ & 0.14 & $16.6(3.2)$ & 19.3 & 0.18 & 3.1 & 1.8 & 28.4 & 15.3 \\
\hline OBE99 & $16.9(1.5)$ & $11.8^{*}$ & 0.21 & $18.4(1.8)$ & 2.4 & 0.23 & 8.9 & 5.6 & 28.3 & 14.5 \\
\hline OFI99 & $17.0(3.8)$ & $29.2^{*}$ & 0.11 & $21.1(6.1)$ & $23.2^{*}$ & 0.22 & 24.1 & 13.1 & 34.1 & 13.4 \\
\hline OGE98 & $10.5(1.0)$ & $10.4 *$ & 0.36 & $11.5(0.9)$ & 5.1 & 0.33 & 9.5 & 3.7 & 33.5 & 10.0 \\
\hline OGE99 & $17.4(2.3)$ & $41.1^{*}$ & 0.33 & $19.5(2.2)$ & $32.2^{*}$ & 0.35 & 12.1 & 7.8 & 32.6 & 11.1 \\
\hline OIR98 & $11.9(0.9)$ & 3.1 & 0.14 & $16.6(1.5)$ & 2.2 & 0.17 & 39.5 & 15.3 & 39.6 & 15.3 \\
\hline OIR99 & 12.4 & 1.0 & 0.17 & $19.1(2.5)$ & $12.0^{*}$ & 0.20 & 54.0 & 21.3 & 34.9 & 13.6 \\
\hline OSW98 & $14.5(1.5)$ & $14.0 *$ & 0.21 & $13.4(2.8)$ & 10.4 & 0.29 & -7.5 & -3.6 & 18.1 & 7.7 \\
\hline OUK98 & $9.8(2.2)$ & 22.9 & 0.19 & $10.8(0.3)$ & 38.0 & 0.24 & 10.2 & 3.3 & 24.1 & 9.6 \\
\hline OUK99 & $22.7(4.4)$ & $37.2^{*}$ & 0.22 & $32.1(5.5)$ & $44.6^{*}$ & 0.20 & 41.4 & 32.2 & 26.7 & 12.1 \\
\hline Average & 14.1 & 22.1 & 0.22 & 17.1 & 19.9 & 0.26 & 21.9 & 12.9 & 26.8 & 16.2 \\
\hline
\end{tabular}

ground biomass (not shown) or leaf area index. Our study also did not indicate any consistency in model bias across all locations. That is, those models which over-predicted to a larger extent than average did so at lower yielding locations, but still under-predicted at higher yielding areas. Similarly models which had a stronger bias for under- or overprediction for $\mathrm{Ca}$ locations were not consistently biased in the same way for Ce predictions. This lack of a consistent trend or bias occurred for all models and model structure groups.

Roughly $60 \%$ of models with lower errors for the calibrated Ca results were among the top models for Ce predictions in all locations (Table 6), emphasizing the importance of 'good' calibration. All modeling groups indicated their calibration approach was to adjust 

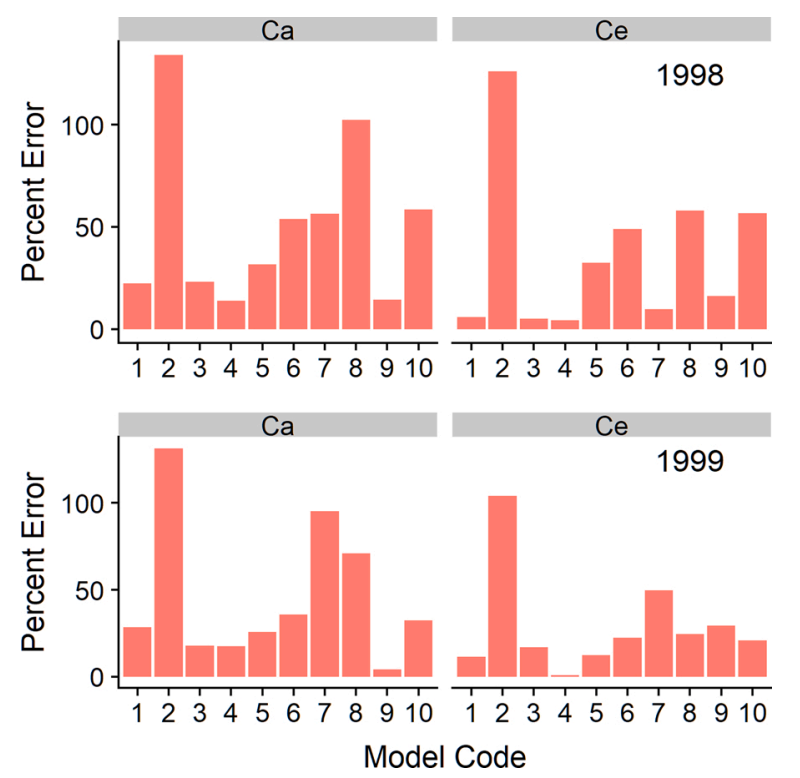

Fig. 5. Percent EOS-yield error versus model code for the FIT location in 1998 (top) and 1999 (bottom) for Ca and Ce sets.
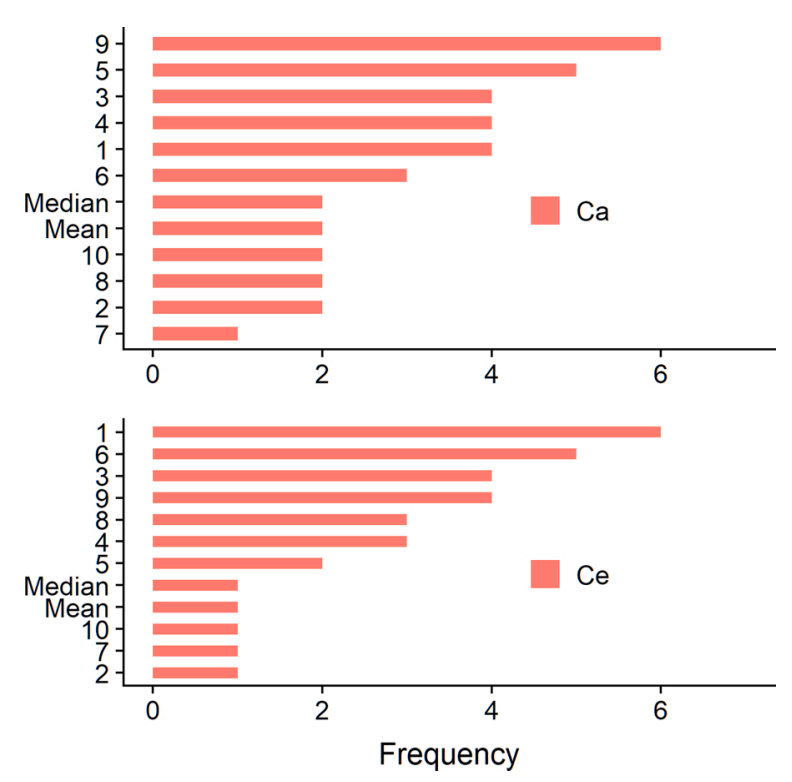

Fig. 6. Number of times for which an individual model is ranked in the top five for six performance metrics (IAD, Perr, MBE, RMSE, RMSRE, and Slope) averaged across locations as in Table 4. Multi-model ensemble mean and median are indicated for reference.

phenology parameters first (those that capture influence of, for example, temperature and/or photoperiod on tuber initiation and maturity dates) followed by growth parameters which is generally the accepted approach (Fleisher et al., 2020). Comparisons of other growth and phenology responses is outside the scope of this manuscript and limited in some locations by data availability. As such, we could not fully evaluate the possibility of models obtaining more accurate yield estimates for the wrong reasons associated with the calibration process.

CHIP data used in this study are unique in that the same cultivar was grown across all locations (De Temmerman et al., 2002a). A single calibration set was obtained for each model by using data pooled across the relevant spatial landscape (Table S1), and this cross-location approach is consistent with most often used modeling practices (Heidmann et al., 2008; Kersebaum et al., 2015). However, results were
Table 6

Models for which EOS-yield percent errors were less than the MME median at each dataset.

\begin{tabular}{llll}
\hline Ambient $\mathrm{CO}_{2}$ & & Elevated $\mathrm{CO}_{2}$ & \\
Location & Model Code & Location & Model Code \\
\hline FGE98 & $3 ; 2 ; 1 ; 9 ; 4$ & FGE98 & $3 ; 1 ; 8 ; 4 ; 5$ \\
FGE99 & $7 ; 2 ; 3 ; 6 ; 5$ & FGE99 & $3 ; 6 ; 7 ; 1 ; 10$ \\
FIT98 & $1 ; 2 ; 4 ; 9 ; 5$ & FIT98 & $4 ; 3 ; 5 ; 8 ; 2$ \\
FIT99 & $1 ; 10 ; 2 ; 7 ; 4$ & FIT99 & $10 ; 6 ; 5 ; 2 ; 1$ \\
OBE98 & $6 ; 5 ; 8 ; 2 ; 7$ & OBE98 & $3 ; 4 ; 5 ; 9 ; 8$ \\
OBE99 & $9 ; 1 ; 3 ; 6 ; 2$ & OBE99 & $3 ; 9 ; 10 ; 8 ; 5$ \\
OFI99 & $10 ; 6 ; 3 ; 7 ; 9$ & OFI99 & $8 ; 2 ; 10 ; 7 ; 6$ \\
OGE98 & $6 ; 8 ; 5 ; 4 ; 1$ & OGE98 & $3 ; 5 ; 4 ; 8 ; 1$ \\
OGE99 & $1 ; 10 ; 2 ; 9 ; 7$ & OGE99 & $2 ; 7 ; 10 ; 6 ; 9$ \\
OIR98 & $7 ; 1 ; 8 ; 9 ; 5$ & OIR98 & $4 ; 10 ; 2 ; 7 ; 6$ \\
OIR99 & $3 ; 6 ; 2 ; 5 ; 9$ & OIR99 & $1 ; 6 ; 9 ; 2 ; 10$ \\
OSW98 & $2 ; 1 ; 5 ; 8 ; 7$ & OSW98 & $3 ; 9 ; 4 ; 7 ; 5$ \\
OUK98 & $2 ; 1 ; 3 ; 10 ; 9$ & OUK98 & $9 ; 3 ; 2 ; 5 ; 1$ \\
OUK99 & $3 ; 9 ; 7 ; 6 ; 5$ & OUK99 & $7 ; 2 ; 1 ; 3 ; 6$ \\
\hline
\end{tabular}

expected to be of higher accuracy because of the quality of these models utilized in the study. For context, the range in calibration coefficient values when models were calibrated individually at each location, instead of cross-location, was indicated in Table S1. There was a broader variation in values for most models, particularly for developmental parameters dependent on temperature or thermal time, which suggested modeling groups were forced to 'compromise' in terms of obtaining a single calibration set that provided a best fit among all locations in this study. However, there did not appear to be a clear relationship between the extent to which calibration coefficient values varied across location versus predictive accuracy for a given model.

The large variation in observed yields across locations, as well as substantial inter-annual yield differences at several sites also likely forced modelers to effectively split the difference between high and low yield locations during the calibration process, which generally resulted in under-predictions for high yields. The analysis of CHIP data in Craigon et al. (2002) showed the effect of $\mathrm{CO}_{2}$ treatment was not consistent ( $\mathrm{p}<0.001$ ) across experiments and sites. Hence it is not completely surprising models struggled to represent / explain the variation in yields in this dataset for $\mathrm{CO}_{2}$ response given that treatments means were not consistently significant for all locations. It is possible that observed potato growth at some locations and years was also constrained by factors other than genetics and environment. The calibration process relies on the use of experimental data under which crop growth is assumed to be at its potential level, and models calibrated using limited growth data would be challenged to accurately replicate yield responses. Several modelers obtained results indicating the presence of both nitrogen and water stress during the growing season for several locations. However, the site data summarized in Table 2 do not indicate potential climate or management problems and an evaluation of experimental results did not find conclusive evidence of limited growth potential (De Temmerman et al., 2002b).

Experimental artifacts from the use of OTC enclosures and FACE data may have impacted the results and the development of input data used for the models. Wolf and Van Oijen (2003) used these same CHIP data with the LPOTCO model and observed poorer correlations between simulated and observed Ce yield responses $\left(\mathrm{R}^{2}=0.28\right)$ as compared to the current results. Their analysis showed a wide variation in measured RUE across the range of temperatures and solar radiation intensities encompassed within the study region which, along with large annual and spatial variations in total biomass, proved difficult to simulate. Problems associated with under-estimation of absorbed radiation (particularly at high latitude sites for OSW, OFI, and OUK), insufficient border row plants, and large heterogeneity in measured data from OTC plots were cited as confounding issues. Similar challenges with other OTC facilities were reported by Ewert et al. (2002) who found it necessary to utilize higher RUE values for their wheat model comparison 
Table 7

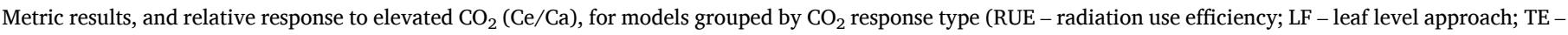
transpiration efficiency). Multi-model ensemble (MME) mean result for all ten models from Table 5 was included for reference.

\begin{tabular}{|c|c|c|c|c|c|c|c|c|c|}
\hline \multirow{3}{*}{ Group } & \multirow{3}{*}{ Models } & \multicolumn{6}{|c|}{ Metric } & \multicolumn{2}{|c|}{ Simulated Ce/Ca Response } \\
\hline & & \multirow[t]{2}{*}{ IA } & \multirow{2}{*}{$\begin{array}{l}\text { Perr } \\
\% \\
\end{array}$} & \multirow{2}{*}{$\begin{array}{l}\text { MBE } \\
\mathrm{Mg} \mathrm{ha}^{-1}\end{array}$} & \multirow[t]{2}{*}{ RMSE } & \multirow{2}{*}{$\begin{array}{l}\text { RMSRE } \\
\%\end{array}$} & \multirow{2}{*}{$\begin{array}{l}\text { Slope } \\
\mathrm{Mg} \mathrm{Mg}^{-1}\end{array}$} & & \\
\hline & & & & & & & & $\%$ & $\mathrm{~kg} \mathrm{ha}^{-1} \mathrm{ppm}^{-1}$ \\
\hline \multicolumn{10}{|c|}{ Ambient $\mathrm{CO}_{2}$ Concentration } \\
\hline RUE & $2 ; 3 ; 4 ; 6 ; 8 ; 10$ & 0.45 & 29 & -0.29 & 5.46 & 34 & 0.96 & 31.1 & 27.3 \\
\hline LF & $5 ; 7 ; 9$ & 0.54 & 24 & -2.09 & 4.76 & 29 & 1.12 & 13.4 & 26.9 \\
\hline $\mathrm{TE}$ & 1 & 0.65 & 20 & -1.59 & 3.43 & 44 & 1.13 & 40.6 & 20.4 \\
\hline MME & & 0.51 & 27 & -0.93 & 4.58 & 33 & 1.06 & 26.8 & 26.5 \\
\hline \multicolumn{10}{|c|}{ Elevated $\mathrm{CO}_{2}$ Concentration } \\
\hline RUE & $2 ; 3 ; 4 ; 6 ; 8 ; 10$ & 0.41 & 30 & 1.01 & 7.23 & 44 & 0.90 & & \\
\hline LF & $5 ; 7 ; 9$ & 0.45 & 26 & -3.71 & 6.73 & 31 & 1.23 & & \\
\hline $\mathrm{TE}$ & 1 & 0.85 & 14 & 0.61 & 3.33 & 17 & 0.97 & & \\
\hline MME & & 0.47 & 27 & -0.55 & 6.14 & 34 & 1.03 & & \\
\hline
\end{tabular}

with OTC or FACE systems. We believe the same OTC and FACE issues plagued the present study as well, particularly that associated with edge effects and plot sizes. It is noteworthy that although percent error was 14 $\%$ or higher across all locations (Table 5), MME predictions were within two standard deviations of observed Ca means for most locations (not shown).

Continued integration of experimentalists with the crop modeling / agricultural decision support community is vital to promote the generation of empirical data needed to fully evaluate, understand, and predict crop response to climate change factors. The term 'sentinel site' was introduced by Boote et al. (2015) to describe experimental datasets which have the minimum details needed to study model improvement, calibration, and application. Sentinel sites can be ranked (e.g. platinum, gold, silver, and copper) based on the availability, comprehensiveness, and quality of the data. Highest ranked sentinel data would include on-site measured hourly or daily weather with no missing gaps, full soil characterization, in-season and end-of-season crop performance, and other components. The CHIP data would be ranked between gold and silver, with limitations due to availability and completeness of data associated with in-season crop performance and characterization of soil, management and weather data. There clearly remains a need for more highly ranked sentinel site data for potato response to $\mathrm{CO}_{2}$. Experimental facilities representative of more natural environments such as OTC, perhaps with larger plot sizes to reduce some edge effects that may be biasing the data, and FACE systems are generally preferred for model evaluation. However, use of more controlled environments such as soil-plant-atmosphere-research (SPAR) facilities (Reddy et al., 2001) which are also located outdoors and have unique measurements for whole plant gas exchange processes can also be useful in this regard as well.

These results partially highlight the need to question further and test assumptions that (a) crop model predictions will be obtained at a high degree of accuracy when predicting climate change responses based on calibration from nominal or current conditions, and (b) sufficient experimental data is available to perform such assessments. Relative yield simulations to elevated $\mathrm{CO}_{2}$ are likely to be more accurate than absolute predictions, particularly when looking at responses at multiple locations or broader spatial scales. While the use of a MME approach is still preferable to that of use of a single model over multiple regions and scenarios, improving the accuracy of individual models that comprise the MME is still crucial. Given the lack of consistency among MME and individual models across all locations, it was not clear what specific areas need to be targeted in model source code to improve performance. Selection of model type for future climate studies for potato would arguably depend on user preference and purpose of the study. For example, RUE or TE based approaches are simpler to parameterize than comparable leaf-level methods. At the same time, Bassu et al. (2014); Durand et al. (2018), and Martre et al. (2015) indicated that models incorporating leaf stomatal conductance were better suited to estimating water use under elevated $\mathrm{CO}_{2}$ conditions. In lieu of additional vigorous testing with additional independent field data (where available), our recommendation is that high quality input data for both ambient and elevated $\mathrm{CO}_{2}$ conditions, where available, should be used for potato model calibration before extrapolating future climate predictions.

\section{Conclusion}

The 10 model potato crop MME used in this study was challenged to replicate Ce yield responses across multiple locations when calibrated only with Ca data. However, percent errors and other performance metrics were similar for calibration Ca datasets as well as predicted Ce responses. In this sense, models with the least calibration error for yield were also those with the least error for Ce predictions. The mechanism by which models simulate the effect of $\mathrm{CO}_{2}$ response on plant growth did not appear to play a large role in performance, with three of the top four highest performing models representing three different structural groups. This implies that at least for the current study, calibration may have been as important as model structure. In contrast to other MME studies, four models also outperformed the MME mean and median in over $50 \%$ of the datasets at either $\mathrm{CO}_{2}$ concentration. Variability among model predictions was similar for both $\mathrm{Ca}$ and Ce datasets, and large location and annual yield variations were present. In agreement with other studies, artifacts associated with OTC and FACE experimental systems related to plot size, border rows, edge effects, and other management influences may have biased the data which subsequently contributed to model calibration difficulties. Nonetheless, this is the first study to evaluate multiple potato model responses to elevated $\mathrm{CO}_{2}$ over multiple locations using just a single variety. While use of a MME is still recommended above that of a single model, modeling studies focused on projected climate impacts should utilize Ce data as part of the individual model calibration process where possible.

\section{Disclosure statement}

Mention of a trademark or proprietary product does not constitute a guarantee or warranty of the product by the US Department of Agriculture and does not imply its approval to the exclusion of other products that also can be suitable. USDA is an equal opportunity provider and employer. All experiments complied with the current laws of the United States, the country in which they were performed.

\section{CRediT authorship contribution statement}

David H. Fleisher: Project administration, Formal analysis, Methodology, Software, Writing - original draft. Bruno Condori: Conceptualization, Methodology, Writing - review \& editing. Carolina Barreda: 
Software, Writing - review \& editing. Herman Berguijs: Software, Writing - review \& editing. Marco Bindi: Software, Writing - review \& editing. Ken Boote: Conceptualization, Writing - review \& editing. Jim Craigon: Data curation, Writing - review \& editing. Frits van Evert: Software, Writing - review \& editing. Andreas Fangmeier: Data curation, Writing - review \& editing. Roberto Ferrise: Software, Writing review \& editing. Sebastian Gayler: Software, Writing - review \& editing. Gerrit Hoogenboom: Conceptualization, Software, Writing review \& editing. Paolo Merante: Software, Writing - review \& editing. Claas Nendel: Software, Writing - review \& editing. Johan Ninanya: Software, Writing - review \& editing. Håkan Pleijel: Data curation, Writing - review \& editing. Dirk Raes: Software, Writing - review \& editing. David A. Ramírez: Software, Writing - review \& editing. Rubi Raymundo: Resources, Software, Writing - review \& editing. Pytrik Reidsma: Software, Writing - review \& editing. João Vasco Silva: Software, Writing - review \& editing. Claudio O. Stöckle: Software, Writing - review \& editing. Iwan Supit: Software, Writing - review \& editing. Tommaso Stella: Software, Writing - review \& editing. Karine Vandermeiren: Data curation, Writing - review \& editing. Pepijn van Oort: Software, Writing - review \& editing. Eline Vanuytrecht: Software, Writing - review \& editing. Virpi Vorne: Data curation, Writing review \& editing. Joost Wolf: Data curation, Software, Writing - review \& editing.

\section{Declaration of Competing Interest}

The authors declare that they have no known competing financial interests or personal relationships that could have appeared to influence the work reported in this paper.

\section{Acknowledgements}

This work was supported by USDA-ARSCRIS-8042-11660-001-00D and the "Root, Tubers and Bananas-RTB" CGIAR Research Program and CGIAR Trust Fund contributors (https://www.cgiar.org/funders/).

\section{Appendix A. Supplementary data}

Supplementary material related to this article can be found, in the online version, at doi:https://doi.org/10.1016/j.eja.2021.126265.

\section{References}

Ahmad, I., Ahmad, B., Boote, K., Hoogenboom, G., 2020. Adaptation strategies for maize production under climate change for semi-arid environments. Eur. J. Agron. 115 https://doi.org/10.1016/j.eja.2020.126040.

Alexander, D.L., Tropsha, A., Winkler, D.A., 2015. Beware of R(2): simple, unambiguous assessment of the prediction accuracy of qsar and qspr models. J. Chem. Inf. Model 55, 1316-1322. https://doi.org/10.1021/acs.jcim.5b00206.

Asseng, S., Ewert, F., Rosenzweig, C., Jones, J.W., Hatfield, J., Ruane, A.C., Boote, K.J. Thorborn, P.J., Rotter, R.P., Cammarano, D., Brisson, N., Basso, B., Martre, P., Aggarwal, P.K., Angulo, C., Bertuzzi, P., Biernath, C., Challinor, A.J., Doltra, J., Gayler, S., Goldberg, R., Grant, R., Heng, L., Hooker, J., Hunt, L.A., Ingwersen, J., Izaurralde, R.C., Kersebaum, K.C., Muller, C., Kumar, N.S., Nendel, C., O'Leary, G., Olesen, J.E., Osborne, T.M., Palosuo, T., Priesack, E., Ripoche, D., Semenov, M.A., Shcherbak, I., Steduto, P., Stockle, C., Stratonovitch, P., Streck, T., Supit, I., Tao, F., Travasso, M., Waha, K., Wallach, D., White, J.W., Williams, J.R., Wolf, J., 2013. Uncertainty in simulating wheat yields under climate change. Nat. Clim. Chang. 3, 827-832. https://doi.org/10.1038/ncliamte1916.

Bassu, S., Brisson, N., Durand, J.L., Boote, K., Lizaso, J., Jones, J.W., Rosenzweig, C., Ruane, A.C., Adam, M., Baron, C., Basso, B., Biernath, C., Boogaard, H., Conijn, S., Corbeels, M., Deryng, D., De Sanctis, G., Gayler, S., Grassini, P., Hatfield, J., Hoek, S., Izaurralde, C., Jongschaap, R., Kemanian, A.R., Kersebaum, K.C., Kim, S.H., Kumar, N.S., Makowski, D., Muller, C., Nendel, C., Priesack, E., Pravia, M.V., Sau, F. Shcherbak, I., Tao, F., Teixeira, E., Timlin, D., Waha, K., 2014. How do various maize crop models vary in their responses to climate change factors? Glob. Chang. Biol. 20, 2301-2320. https://doi.org/10.1111/gcb.12520.

Boote, K.J., Jones, J.W., White, J.W., Asseng, S., Lizaso, J.I., 2013. Putting mechanisms into crop production models. Plant Cell Environ. 36, 1658-1672. https://doi.org/ 10.1111/pce.12119.

Boote, K.J., Porter, C.H., Jones, J.W., Thorburn, P.J., Kersebaum, K.C., Hoogenboom, G., White, J.W., Hatfield, J.L., 2015. Sentinel site data for model improvement definition and characterization. In: Hatfield, J.L., Fleisher, D. (Eds.), Improving
Modeling Tools to Assess Climate Change Effects on Crop Response. ASA, CSSA, and SSSA, Madison, WI, USA. https://doi.org/10.2134/advagricsystmodel7.2014.0019.

Carter, T.R., 2013. Agricultural impacts: multi-model yield projections. Nat. Clim. Chang. 3, 784-786. https://doi.org/10.1038/nclimate1995.

Chen, X., Wang, L., Niu, Z., Zhang, M., Li, Ca., Li, J., 2020. The effects of projected climate change and extreme climate on maize and rice in the Yangtze River Basin, China. Agric. For. Meteorol. 282-283. https://doi.org/10.1016/j. agrformet.2019.107867.

Craigon, J., Fangmeier, A., Jones, M., Donnelly, A., Bindi, M., De Temmerman, L., Persson, K., Ojanpera, K., 2002. Growth and marketable-yield responses of potato to increased CO2 and ozone. Eur. J. Agron. 17, 273-289. https://doi.org/10.1016/ S1161-0301(02)00066-7.

Dathe, A., Fleisher, D.H., Timlin, D.J., Fisher, J.K., Reddy, V.R., 2014. Modeling potato root growth and water uptake under water stress conditions. Agric. For. Meteorol. 194, 37-49. https://doi.org/10.1016/j.agrformet.2014.03.011.

De Temmerman, L., Hacour, A., Guns, M., 2002a. Changing climate and potential impacts on potato yield and quality CHIP: introduction, aims and methodology. Eur. J. Agron. 17, 233-242. https://doi.org/10.1016/S1161-0301(02)00063-1.

De Temmerman, L., Wolf, J., Colls, J.J., Bindi, M., Fangmeier, A., Finnan, J.M., Ojanpera, K., Pleijel, H., 2002b. Effect of climatic conditions on tuber yield (Solanum tuberosum L.) in the European' CHIP' experiments. Eur. J. Agron. 17, 243-255. https://doi.org/10.1016/S1161-0301(02)00064-3.

Durand, J.-L., Delusca, K., Boote, K., Lizaso, J., Manderscheid, R., Weigel, H.J., Ruane, A. C., Rosenzweig, C., Jones, J., Ahuja, L., Anapalli, S., Basso, B., Baron, C., Bertuzzi, P., Biernath, C., Deryng, D., Ewert, F., Gaiser, T., Gayler, S., Heinlein, F., Kersebaum, K. C., Kim, S.-H., Müller, C., Nendel, C., Olioso, A., Priesack, E., Villegas, J.R., Ripoche, D., Rötter, R.P., Seidel, S.I., Srivastava, A., Tao, F., Timlin, D., Twine, T., Wang, E., Webber, H., Zhao, Z., 2018. How accurately do maize crop models simulate the interactions of atmospheric $\mathrm{CO} 2$ concentration levels with limited water supply on water use and yield? Eur. J. Agron. 100, 67-75. https://doi.org/10.1016/ j.eja.2017.01.002.

Ewert, F., Rodriguez, D., Jamieson, P., Semenov, M.A., Mitchell, R.A.C., Goudriaan, J., Porter, J.R., Kimball, B.A., Pinter Jr., P.J., Manderscheid, R., Weigel, H.J., Fangmeier, A., Fereres, E., Villalobos, F.J., 2002. Effects of elevated CO2 and drought on wheat: testing crop simulation models for different experimental and climate conditions. Agric. Ecosyst. Environ. 249-266. https://doi.org/10.1016/ S0167-8809(01)00352-8.

Fleisher, D.H., Timlin, D., Reddy, K., Reddy, V.R., Yang, Y., Kim, S.-H., 2010a. Effects of $\mathrm{CO} 2$ and temperature on crops: lessons from SPAR growth chambers. In: Hatfield, J. L., Fleisher, D. (Eds.), Improving Modeling Tools to Assess Climate Change Effects on Crop Response. American Society of Agronomy, Inc., Crop Science Society of America, Inc., Soil Science Society of America, Inc., Madison, WI USA, pp. 69-80. https://doi.org/10.2134/advagricsystmodel7.2014.0018.5 https://doi.org/.

Fleisher, D.H., Timlin, D.J., Yang, Y., Reddy, V.R., 2010b. Simulation of potato gas exchange rates using SPUDSIM. Agric. For. Meteorol. 150, 432-442. https://doi.org/ 10.1016/j.agrformet.2010.01.005.

Fleisher, D.H., Condori, B., Quiroz, R., Alva, A., Asseng, S., Barreda, C., Bindi, M., Boote, K.J., Ferrise, R., Franke, A.C., Govindakrishnan, P.M., Harahagazwe, D., Hoogenboom, G., Naresh Kumar, S., Merante, P., Nendel, C., Olesen, J.E., Parker, P. S., Raes, D., Raymundo, R., Ruane, A.C., Stockle, C., Supit, I., Vanuytrecht, E., Wolf, J., Woli, P., 2017. A potato model intercomparison across varying climates and productivity levels. Glob. Chang. Biol. 23, 1258-1281. https://doi.org/10.1111/ gcb.13411.

Fleisher, D.H., Haynes, K.G., Timlin, D.J., 2020. Cultivar coefficient stability and effects on yield projections in the SPUDSIM model. Agron. J. 1-16. https://doi.org/ 10.1002/agj2.20070.

Harahagazwe, D., Condori, B., Barreda, C., Bararyenya, A., Byarugaba, A.A., Kude, D.A., Lung'aho, C., Martinho, C., Mbiri, D., Nasona, B., Ochieng, B., Onditi, J. Randrianaivoarivony, J.M., Tankou, C.M., Worku, A., Schulte-Geldermann, E., Mares, V., Mendiburu d, F., Quiroz, R.Q., 2018. How big is the potato (Solanum tuberosum L.) yield gap in Sub-Saharan Africa and why? A participatory approach. Open Agric. 3, 180-189. https://doi.org/10.1515/opag-2018-0019.

Hasegawa, T., Li, T., Yin, X., Zhu, Y., Boote, K., Baker, J., Bregaglio, S., Buis, S., Confalonieri, R., Fugice, J., Fumoto, T., Gaydon, D., Kumar, S.N., Lafarge, T., Marcaida Iii, M., Masutomi, Y., Nakagawa, H., Oriol, P., Ruget, F., Singh, U., Tang, L., Tao, F., Wakatsuki, H., Wallach, D., Wang, Y., Wilson, L.T., Yang, L., Yang, Y., Yoshida, H., Zhang, Z., Zhu, J., 2017. Causes of variation among rice models in yield response to $\mathrm{CO} 2$ examined with free-air $\mathrm{CO} 2$ Enrichment and growth chamber experiments. Sci. Rep. 7, 14858 https://doi.org/10.1038/s41598-01713582-y.

Heidmann, T., Tofteng, C., Abrahamsen, P., Plauborg, F., Hansen, S., Battilani, A., Coutinho, J., Doležal, F., Mazurczyk, W., Ruiz, J.D.R., Takáč, J., Vacek, J., 2008. Calibration procedure for a potato crop growth model using information from across Europe. Ecol. Modell. 211, 209-223. https://doi.org/10.1016/j. ecolmodel.2007.09.008.

Hoogenboom, G., Jones, J.W., Wilkens, P.W., Porter, C.H., Boote, K.J., Hunt, L.A., Singh, U., Lizaso, J.I., White, J.W., Uryasev, O., Ogoshi, R., Koo, J., Shelia, V., Tsuji, G.Y., 2015. Decision Support System for Agrotechnology Transfer (DSSAT). version 4.6 (www.dssat.net). DSSAT Foundation, Prosser, Washington.

Hoogenboom, G., Porter, C.H., Boote, K.J., Shelia, V., Wilkens, P.W., Singh, U., White, J. W., Asseng, S., Lizaso, J., Moreno, L.P., Pavan, W., Ogoshi, R., Hunt, L.A., Tsuji, G.Y., Jones, J.W., 2019. The DSSAT crop modeling ecosystem. In: Boote, K.J. (Ed.), Advances in Crop Modeling for Sustainable Agriculture. Burleigh Dodds Science Publishing, Cambridge, United Kingdom. https://doi.org/10.19103/ AS.2019.0061.10. 
Jansen, D.M., 2008. Beschrijving van TIPSTAR: hét simulatiemodel voor groei en productie van zetmeelaardappelen [Description of TIPSTAR: the simulation model for growth and production of starch potatoes]. Plant Research International, Wageningen. Available online at http://edepot.wur.nl/27135.

Kersebaum, K.C., Boote, K.J., Jorgenson, J.S., Nendel, C., Bindi, M., Frühauf, C., Gaiser, T., Hoogenboom, G., Kollas, C., Olesen, J.E., Rötter, R.P., Ruget, F., Thorburn, P.J., Trnka, M., Wegehenkel, M., 2015. Analysis and classification of data sets for calibration and validation of agro-ecosystem models. Environ. Model. Softw. 72, 402-417. https://doi.org/10.1016/j.envsoft.2015.05.009.

Kim, S.H., Lieth, J.H., 2003. A coupled model of photosynthesis, stomatal conductance and transpiration for a rose leaf (Rosa hybrida L.). Ann. Bot. 91, 771-781. https:// doi.org/10.1093/aob/mcg080.

Kim, S.-H., Yang, Y., Timlin, D.J., Fleisher, D.H., Dathe, A., Reddy, V.R., Staver, K., 2012. Modeling temperature responses of leaf growth, development, and biomass in maize with MAIZSIM. Agron. J. 104, 1523. https://doi.org/10.2134/agronj2011.0321.

Kimball, B.A., 2011. Lessons from FACE: $\mathrm{CO}_{2}$ effects and interactions with water, nitrogen and temperature. In: Hillel, D., Rosenzweig, C. (Eds.), Handbook of Climate Change and Agroecosystems: Impacts, Adaptation, and Mitigation. Imperial College Press, London, UK, pp. 87-107. https://doi.org/10.1142/9781848166561_0006.

Knutti, R., Furrer, R., Tebaldi, C., Cermak, J., Meehl, G.A., 2010. Challenges in combining projections from multiple climate models. J. Clim. 23, 2739-2758. https://doi.org/10.1175/2009jcli3361.1.

Li, T., Hasegawa, T., Yin, X., Zhu, Y., Boote, K., Adam, M., Bregaglio, S., Buis, S., Confalonieri, R., Fumoto, T., Gaydon, D., Marcaida 3rd, M., Nakagawa, H., Oriol, P., Ruane, A.C., Ruget, F., Singh, B., Singh, U., Tang, L., Tao, F., Wilkens, P., Yoshida, H., Zhang, Z., Bouman, B., 2015. Uncertainties in predicting rice yield by current crop models under a wide range of climatic conditions. Glob. Chang. Biol. 21, 1328-1341. https://doi.org/10.1111/gcb.12758.

Marin, F.R., Thorburn, P.J., Nassif, D.S.P., Costa, L.G., 2015. Sugarcane model intercomparison: structural differences and uncertainties under current and potential future climates. Environ. Model. Softw. 72, 372-386. https://doi.org/ 10.1016/j.envsoft.2015.02.019.

Martre, P., Wallach, D., Asseng, S., Ewert, F., Jones, J.W., Rotter, R.P., Boote, K.J., Ruane, A.C., Thorburn, P.J., Cammarano, D., Hatfield, J.L., Rosenzweig, C., Aggarwal, P.K., Angulo, C., Basso, B., Bertuzzi, P., Biernath, C., Brisson, N., Challinor, A.J., Doltra, J., Gayler, S., Goldberg, R., Grant, R.F., Heng, L., Hooker, J., Hunt, L.A., Ingwersen, J., Izaurralde, R.C., Kersebaum, K.C., Muller, C., Kumar, S.N., Nendel, C., O'Leary, G., Olesen, J.E., Osborne, T.M., Palosuo, T., Priesack, E., Ripoche, D., Semenov, M.A., Shcherbak, I., Steduto, P., Stockle, C.O., Stratonovitch, P., Streck, T., Supit, I., Tao, F., Travasso, M., Waha, K., White, J.W., Wolf, J., 2015. Multimodel ensembles of wheat growth: many models are better than one. Glob. Chang. Biol. 21, 911-925. https://doi.org/10.1111/gcb.12768.

Nendel, C., Berg, M., Kersebaum, K.C., Mirschel, W., Specka, X., Wegehenkel, M., Wenkel, K.O., Wieland, R., 2011. The MONICA model: Testing predictability for crop growth, soil moisture and nitrogen dynamics. Ecol. Model. 222, 1614-1625. https:// doi.org/10.1016/j.ecolmodel.2011.02.018.

Poorter, H., J B.H, van Dusschoten, D., Climent, J., Postma, J.A., 2012. Pot size matters: a meta-analysis of the effects of rooting volume on plant growth. Funct. Plant Biol. 39, 839-850. https://doi.org/10.1071/FP12049.
Raymundo, R., Asseng, S., Prassad, R., Kleinwechter, U., Concha, J., Condori, B., Bowen, W., Wolf, J., Olesen, J.E., Dong, Q., Zotarelli, L., Gastelo, M., Alva, A., Travasso, M., Quiroz, R., Arora, V., Graham, W., Porter, C., 2017. Performance of the SUBSTOR-potato model across contrasting growing conditions. Field Crops Res. 202, 57-76. https://doi.org/10.1016/j.fcr.2016.04.012.

Reddy, K.R., Hodges, H.F., Read, J.J., McKinion, J.M., Baker, J.T., Tarpley, L., Reddy, V. R., 2001. Soil-Plant-Atmosphere-Research (SPAR) facility: a tool for plant research and modeling. Biotronics 30, 27-50.

Resop, J.P., Fleisher, D.H., Timlin, D.J., Mutiibwa, D., Reddy, V.R., 2016. Climate, water management, and land use: estimating potential potato and corn production in the U.S. Northeastern Seaboard Region. Trans. Asabe 59, 1539-1553. https://doi.org/ 10.13031/trans.59.11748.

Shibu, M.E., Leffelaar, P.A., Van Keulen, H., Aggarwal, P.K., 2010. LINTUL3, a simulation model for nitrogen-limited situations: Application to rice. Eur. J. Agron. 32, 255-271.

Steduto, P., Hsiao, T.C., Raes, D., Fereres, E., 2009. AquaCrop-the FAO crop model to simulate yield response to water: I. Concepts and underlying principles. Agron. J. 101, 426. https://doi.org/10.2134/agronj2008.0139s.

Stenger, R., Priesach, E., Barkle, G., Sperr, C., et al., 1999. Expert-N, a tool for simulating nitrogen and carbon dynamics in the soil-plant-atmosphere system. In: Tomer, M. (Ed.), NZ land treatment collective, Proceedings of technical session 20: modelling of land treatment systems 19-28.

Stockle, C.O., Donatelli, M., Nelson, R., 2003. CropSyst, a cropping systems simulation model. Eur. J. Agron. 18, 289-307. https://doi.org/10.1016/S1161-0301(02)001090 .

Tubiello, F.N., Ewert, F., 2002. Simulating the effects of elevated CO2 on crops: approaches and applications for climate change. Eur. J. Agron. 18, 57-74. https:// doi.org/10.1016/S1161-0301(02)00097-7.

Van Oijen, M., Ewert, F., 1999. The eff ;ects of climatic variation in Europe on the yield response of spring wheat cv. Minaret to elevated CO2and O3: an analysis of open-top chamber experiments by means of two crop growth simulation models. Eur. J. Agron. 10, 249-264. https://doi.org/10.1016/S1161-0301(99)00014-3.

Wallach, D., Mearns, L.O., Ruane, A.C., Rötter, R.P., Asseng, S., 2016. Lessons from climate modeling on the design and use of ensembles for crop modeling. Clim. Change 139, 551-564. https://doi.org/10.1007/s10584-016-1803-1.

Wang, B., Feng, P., Liu, D.L., Waters, C., 2020. Modelling biophysical vulnerability of wheat to future climate change: a case study in the eastern Australian wheat belt. Ecol. Indic. 114 https://doi.org/10.1016/j.ecolind.2020.106290.

Willmott, C.J., Robeson, S.M., Matsuura, K., 2012. A refined index of model performance. Int. J. Climatol. 32, 2088-2094. https://doi.org/10.1002/joc. 2419.

Wolf, J., Van Oijen, M., 2002. Modelling the dependence of European potato yields on changes in climate and CO2. Agric. For. Meteorol. 112, 217-231. https://doi.org/ 10.1016/S0168-1923(02)00061-8.

Wolf, J., Van Oijen, M., 2003. Model simulation of effects of changes in climate and atmospheric CO2 and O-3 on tuber yield potential of potato (cv. Bintje) in the European Union. Agric. Ecosyst. Environ. 94, 141-157. https://doi.org/10.1016/ S0167-8809(02)00029-4.

Xiao, D., Liu, D.L., Wang, B., Feng, P., Waters, C., 2020. Designing high-yielding maize ideotypes to adapt changing climate in the North China Plain. Agric. Syst. 181 https://doi.org/10.1016/j.agsy.2020.102805. 